\title{
CAMA
}

Centre for Applied Macroeconomic Analysis

\section{Unconventional monetary policy: interest rates and low inflation: A review of literature and methods}

\section{CAMA Working Paper 29/2017 April 2017}

\section{Mariarosaria Comunale}

Economics Department, Bank of Lithuania and

Centre for Applied Macroeconomic Analysis, ANU

\section{Jonas Striaukas}

Louvain School of Management

\begin{abstract}
In this paper, we review a range of approaches used to capture monetary policy in a period of Zero Lower Bound (ZLB). We concentrate here on methods closely linked to interest rates, which include: spreads, synthetic indices from principal component analysis, and different shadow rates. Next, we calculate these measures for the euro area, draw comparisons among different approaches, and look at the effects on main macroeconomic variables, with a special focus on inflation. By and large, the impact of unconventional monetary policy shocks on inflation is found to be significantly positive across studies and methods. Finally, we summarize the literature on the Natural Real Rate of Interest. This overview may help to assess how long low (real) interest rates in a ZLB stay in place, potentially leading to more accurate policy recommendations.
\end{abstract}




\section{Keywords}

Unconventional monetary policy, zero lower bound, shadow rates, natural interest rate, inflation.

\section{JEL Classification}

E43, E52, E58, F42

\section{Address for correspondence:}

(E) cama.admin@anu.edu.au

ISSN 2206-0332

The Centre for Applied Macroeconomic Analysis in the Crawford School of Public Policy has been established to build strong links between professional macroeconomists. It provides a forum for quality macroeconomic research and discussion of policy issues between academia, government and the private sector.

The Crawford School of Public Policy is the Australian National University's public policy school, serving and influencing Australia, Asia and the Pacific through advanced policy research, graduate and executive education, and policy impact. 


\title{
Unconventional monetary policy: interest rates and low inflation: A review of literature and methods
}

\author{
Mariarosaria Comunale ${ }^{12}$ and Jonas Striaukas ${ }^{3}$ \\ April 2017
}

\begin{abstract}
In this paper, we review a range of approaches used to capture monetary policy in a period of Zero Lower Bound (ZLB). We concentrate here on methods closely linked to interest rates, which include: spreads, synthetic indices from principal component analysis, and different shadow rates. Next, we calculate these measures for the euro area, draw comparisons among different approaches, and look at the effects on main macroeconomic variables, with a special focus on inflation. By and large, the impact of unconventional monetary policy shocks on inflation is found to be significantly positive across studies and methods. Finally, we summarize the literature on the Natural Real Rate of Interest. This overview may help to assess how long low (real) interest rates in a ZLB stay in place, potentially leading to more accurate policy recommendations.
\end{abstract}

Keywords: Unconventional monetary policy; zero lower bound; shadow rates; natural interest rate; inflation.

JEL classification: E43; E52; E58; F42

\footnotetext{
${ }^{1}$ Principal Economist, Applied Macroeconomic Research Division, Economics Department, Bank of Lithuania, Totorių g. 4, LT01121 Vilnius (Lithuania). Email: MComunale@lb.lt; Phone: +370 (5) 2680103.

${ }^{2}$ Research Associate Centre for Applied Macroeconomic Analysis, The Australian National University, Canberra.

3 Research Student, Louvain School of Management, Place de Doyens, à 1348 Louvain-la-Neuve (Belgium). Email: jonas.striaukas@gmail.com.
}

This project has been undertaken while Jonas Striaukas was Specialist at the Center for Excellence in Finance and Economic Research, Bank of Lithuania. We are very thankful to Mihnea Constantinescu and Rasa Stasiukynaite for their comments and to the Working Group on Econometric Modelling (ECB, ESCB) for discussion on the Natural Rate of Interest. We would also like to thank Borek Vašíček (EU Commission) for his kind help with the synthetic index. We thank Martin Feldkircher for the data and discussion about the Effective Monetary Stimulus. We acknowledge the useful help provided by Ieva Žvinakyte in downloading the data and we thank Sara Tropper for proofreading.

The conclusions expressed here are those of the authors and do not necessarily represent the official views of the Bank of Lithuania. 


\section{Introduction}

A range of approaches has been identified for capturing monetary policy in a period of Zero Lower Bound (hereafter, ZLB) and analyzing its impact on inflation and other macroeconomic variables. The question of how to properly design a measure of the stance is a crucial one, because the moment that the ZLB is reached, a discontinuity emerges and short-term interest rates cease to convey useful information (Lombardi and Zhu, 2014). We will consider the main methods that are linked to interest rates, leaving aside various alternatives that entail changes in size and composition in the balance sheet of the central banks (Pattipeilohy et al. 2013). Moreover, we take into account a new strand of literature that has proposed an alternative to the above-mentioned measures. ${ }^{4}$ In this view, rather than measuring a rate or index to account for the information embedded in a period of ZLB, one assesses the accuracy of conventional policies in order to grasp the necessary duration of unconventional measures. We will refer to this natural (or equilibrium) measure as the Natural Real Rate of Interest (hereafter, NRR).

In the first chapter of the paper, we tackle the main methods applied in the literature to convey the information in a ZLB environment, which involve various forms of interest rates. These are highly interrelated and can be summarized as follows: i) combinations of different rates or spreads, i.e. the spread between long and shortterm interest rates, a combination of short-term rates and corporate spreads or the "economic stimulus measure," which aggregates expected short rates relative to their long-run expectation; ii) synthetic indices from a principal component or principal factor analysis, which may include interest rates; and iii) measures of shadow rates and related measures, such as the Effective Monetary Stimulus (Krippner, 2016; Halberstadt and Krippner, 2016). As shadow rates have been defined in several ways in the literature, we covered different methodologies in this paper.

In the second section of this review, we calculate for the euro area both a synthetic index, using Principal Component Analysis in the spirit of Kucharčuková et al. (2016), and a measure of shadow rates, based on Xia and Wu (2016) and Bauer and Rudebusch (2015). We also compare these different approaches and look at the effects on main macroeconomic variables, with a special focus on inflation and the euro area.

Finally, we provide an overview on the NRR literature to assess for how long low (real) interest rates in a ZLB can stay in place (Laubach and Williams, 2015). The resulting interest rate gap, i.e. the difference between the NRR and its estimated natural level, may turn out to be a valuable policy-recommendation tool. We describe the drawbacks of this approach as well, particularly its lack of robustness. In that regard, we also propose ways to improve such estimates.

We found no single indicator which stands out as the best from the pool suggested by the literature; each of them has advantages and disadvantages. These issues are mainly related to their comparability with the actual rates, macroeconomic information, and robustness of estimations. As for the NRR, this measure also has some drawbacks, especially with respect to robustness. We discuss some ways to improve it, toward better policy assessment and recommendations. Lastly, the impact on inflation of Unconventional Monetary Policy (UMP) shocks is found to be positive in most of the surveyed studies and methods.

The paper is organized as follows: section 2 addresses the recent literature, section 3 draws comparisons and provides comments on methods, analyzing their effects especially on inflation, section 4 presents the calculated synthetic index and shadow rates, section 5 summarizes the literature and the main findings on the NRR, and section 6 concludes.

\footnotetext{
${ }^{4}$ Recently, Pescatori and Turunen (2015) built a bridge between the two approaches, introducing the shadow rate into the determination of the NRR. Re-estimating the model with shadow rates seems to suggest an even lower NRR, but given the larger implied interest rate gaps, there is also more policy accommodation (see Chapter 5).
} 


\section{Literature review on interest rates in ZLB}

As mentioned above, the main methods applied in the literature, which involve interest rates, are as follows: i) combinations of different rates or spreads; ii) synthetic indices from a principal component or principal factor analysis, which may include interest rates; and iii) measures of shadow rates.

\subsection{Combinations of different rates or spreads}

Among the most popular methods used to identify unconventional measures, one is a combination of short and long-term rates. In that regard, Baumeister and Benati $(2010,2013)$ identify a non-conventional monetary shock in a Bayesian time-varying parameter structural vector autoregressive (TVP-SVAR) framework by using the spread between long and short-term interest rates in the cases of the euro area, Japan, U.S. and U.K. This interest rate spread complements the traditional short-term interest rate, because the shortterm interest rate is constrained by the ZLB, and the spread should instead capture the effect of the large-scale asset purchases on the longer-term rates. The Federal Reserve and the European Central Bank (ECB) have pursued large-scale asset purchase programs aimed at lowering the longer-term interest rate in order to support the recovery in aggregate demand. The key finding in Baumeister and Benati $(2010,2013)$ is that in all the analyzed countries, a decrease in the long-term yield spread (1\% negative shock) exerts a powerful effect on both output growth and inflation.

Concerning the application of this UMP measure, a recent occasional paper by the ECB (2017) uses it to look at the drivers of inflation in the euro area in recent periods. The UMP shocks are indeed identified by applying a spread $a$ la Baumeister and Benati (2010, 2013), as the difference between the 10-year government benchmark bond yield and the Euro OverNight Index Average (EONIA). According to this paper, the drivers of low inflation in 2009 were mostly/generally external in nature, while the further low-inflation episode has been driven more by internal euro-area factors and demand than by supply forces. Bobeica and Jarocinski (2017), who also apply the spread for their identifications in a structural BVAR setup, likewise stress that the two episodes in the euro area appear to be of different nature, and they arrive at similar conclusions. Global variables are the crucial factors for the "missing disinflation" period. Weak domestic shocks are important for understanding the euro-area "missing inflation".

A rather similar approach to that taken by Baumeister and Benati $(2010,2013)$ is applied in Chen et al. (2015) for assessing the domestic and foreign effects of U.S. unconventional policies in a global vector error correction model (GVECM). ${ }^{5}$ The authors capture the effect of UMP by using two indicators: the U.S. term spread between the 10-year and 3-month Treasury yields (as in Baumeister and Benati, 2010; 2013), and the U.S. corporate spread between the Bank of America Merrill Lynch US corporate AAA bond yield and the effective Federal Reserve System (FED) rate. To justify their choices, they refer to Blinder (2010), suggesting that central banks use unconventional tools to "reduce interest rate spreads" - such as "term premiums and/or risk premiums", buying long-term Treasuries, or using quantitative easing (QE) to target "risk or liquidity spreads". Chen et al. (2015) conclude that QE measures that lower the U.S. corporate spread have had a sizeable impact, varying significantly across regions and individual economies. ${ }^{6}$

A drawback of this approach is that short-term and corporate spreads are not monetary instruments per se and they fluctuate for many different reasons (Lombardi and Zhu, 2014).

\footnotetext{
${ }^{5}$ GVECM was developed by Pesaran, Schuermann and Weiner (2004).

${ }^{6}$ This is in line with Blinder's (2012) claims that purchasing U.S. Treasuries to lower the term spread may be a weak tool, while reducing the risk premium by acquiring private-sector assets is more effective.
} 


\subsection{Synthetic indices}

Alternatively, one can construct synthetic indices by applying a principal factor analysis with different macro-financial variables, including short-term rates. In the latter case, Kucharčuková et al. (2016) offer an interesting application to the euro area. The index is based on 14 variables reflecting the monetary conditions for the euro area, which are divided into 4 categories: interest rates and spreads, monetary aggregates, selected ECB balance sheet items and, additionally, the exchange rate vis-à-vis the U.S. dollar. The authors also provides an application of this synthetic index by looking at the effect of euro-area monetary policy inside and outside the euro area. They do not include any macroeconomic variable. They use a block-exogeneity VAR model, and the main outcome for the euro area is that the transmission of UMP to prices is quicker. Conventional monetary policy affects the short-term interest rate first, and its impact is intermediated by longterm interest rates and, finally, investment (in the case of UMP). However, the transmission starts immediately by affecting long-term interest rates via portfolio balancing and signaling, which affects inflation expectations. This can substantially shorten the horizon at which the impact occurs.

In another recent paper, Bluwstein and Canova (2016) identify a UMP policy shock in the euro area by using the principal component method, applying it in a Bayesian mixed frequency Structural vector autoregressive (S-VAR) setup. This synthetic index is computed using U.S. and U.K. (conventional and unconventional) policy measures, global real economy indicators, oil prices, Eastern European and EU (excluding euro-area) financial indicators, global trade price, and global equity indicators. Moreover, nominal interest rates are also added to the model to identify conventional monetary policy shocks. The authors conclude that for the euro area, following a UMP shock, inflation significantly and persistently increases, while real activity responses are negative on impact and then insignificant. In case of conventional monetary policy shock, inflation does not show a significant reaction.

\subsection{Shadow rates}

Lastly, the use of shadow rates has also been applied to produce a summary metric for the stance of UMP. Having a shadow rate has intuitive appeal, because when it is positive it equals the actual short rate, but the shadow rate is free to evolve to negative levels after the actual short rate becomes constrained by the ZLB. As such, the shadow rate indicates how the funds rate would have behaved if policymakers could have driven it negative. Moreover, this rate may be also easier to understand than a synthetic indicator from principal component analyses and can be directly comparable with the short-term interest rate in normal times (Lombardi and Zhu, 2014). As pointed out by Krippner (2014), there are some drawbacks when we have negative shadow rates, because these are not an actual interest rate faced by economic agents and may vary with the practical choices underlying their calculations. In particular, they depend on the specification of the shadow/ZLB model and the data and method used for estimation. Lombardi and Zhu (2014) and Wu and Xia (2016), in that regard, claim that the common dynamics among different shadow rates point to the same economic conclusion, and also provide evidence that the shadow rates can effectively summarize relevant information at ZLB.

In the literature, one finds different ways to define shadow rates and different empirical approaches. The most-often applied methodologies to compute shadow rates are dynamic factor models (Lombardi and Zhu, 2014) and multifactor shadow rate term structure models (SRTSM), including those that count for the lower bound in alternative ways (Bauer and Rudebusch, 2015; Lemke and Vladu, 2015; Wu and Xia, 2016; Kortela, 2016). ${ }^{7,8}$

\footnotetext{
${ }^{7}$ See also Table 2
} 
Lombardi and Zhu (2014) propose a new "shadow policy rate" for the U.S. economy, using a large set of data representing the various factors and characteristics of the U.S. Federal Reserve's policy stance. To do so, they map changes in all other monetary policy variables onto a single shadow rate, based on estimated historical relationships. ${ }^{9}$ They claim that their set of variables is suitable to exploit the basis of U.S. monetary policy. The set includes: interest rates, monetary aggregates, and the Federal Reserve balance sheet (assets and liabilities). Hence, the aspect that relates to change in size and composition in the balance sheet of the central banks is covered as well. Next, they use a dynamic factor model with missing observations to extract common components from this large set of variables. In this way, they retrieve a shadow federal funds rate that maps onto it the changes in other indicators of monetary policy. Their approach seems like a more refined version of a synthetic index. In a VAR, they also look at monetary policy shocks, conventional and otherwise. Monetary policy shocks estimated with short-term rates would severely understate the true extent of monetary expansion afforded by non-standard policy measures implemented after the breakout of the financial crisis.

A shadow rate that is linked to yield curves and includes other macroeconomic effects was built by using multifactor SRTSM (Bauer and Rudebusch, 2015; Wu and Xia, 2016; Kortela, 2016).

Bauer and Rudebusch (2015), for instance, show that when the nominal term structure is constrained by the ZLB, the addition of macroeconomic variables to the information set is useful for inference about the future evolution of the yield curve. The authors indeed apply for the U.S. a multifactor shadow rate term structure model ${ }^{10}$ using a simulation-based method, and also provide a more macro-finance term structure model. Here the short rate and all other model-implied interest rates cannot go below a minimum rate set at zero. The authors stress the differences in methodologies to construct shadow rates; Krippner (2014) and Wu and Xia (2016) also use the conditional mean for the short rate to obtain forward rates for the shadow-rate model, but they plug in the affine forward rates, significantly increasing the accuracy of the approximation. The authors also show a model with macro-finance information, because in a ZLB they provide important additional information for forecasting future yields, particularly for predicting how long the policy rate will remain near zero. Their main aim here is indeed to check for the expected duration of the ZLB period, which can provide a useful measure of the stance of monetary policy and the tightness of the ZLB. However, the authors admit a shortcoming of their ZLB term structure model, which is the assumption of stationarity across pre-ZLB and ZLB periods.

A multifactor SRTSM similar to Bauer and Rudebusch (2015) has been also used by Lemke and Vladu (2015) and Kortela (2016) ${ }^{11}$ to model the dynamics of the euro-area yield curve. In the first paper, the lower bound is not set to zero, but is estimated at 10 basis points. ${ }^{12}$ The latter is defined as "elastic bound", and they refer to the estimate as the "effective lower bound". The authors find that the estimated shadow-rate term structure model performs attractively with respect to the euro-area yield curve data. The ECB interest rate cut in June 2014 spurred the authors to investigate the reaction of the term structure of interest rates to changes in this "effective lower bound" by using the forward curve approximation by Wu and Xia (2016). The authors further find that the effect of a shock to the lower bound depends on the initial conditions of the yield curve. Kortela (2016), starting from this result, suggests that a time-varying lower bound might be appropriate for the euro area, and that such a model outperforms the constant lower bound model in euro-area data. This

\footnotetext{
${ }^{8}$ These models evolved from the Gaussian affine term structure models (G-ATSMs) (Diebold and Rudebusch, 2013) (see Section 3.2.1).

${ }^{9}$ Here the reconstruction of missing values for key variables is based on the expectation maximization (EM) algorithm, driven by the evolution of the fully observed series and historical patterns of their correlations with the series with missing observations.

${ }^{10}$ It is based on analytical representation for bond prices in dynamic term structure models (DTSMs), both Gaussian and shadow.

${ }^{11}$ The linear Gaussian factor dynamics are set as driving forces exactly as in the G-ATSM, but it is the shadow rate rather than the actual short-term rate that is driven by those factors.

${ }^{12}$ This is based on the term structure dynamics during a time of historically low euro-area interest rates in the last part of the sample (October 2011 to April 2014).
} 
finding is confirmed by Lemke and Vladu (2016). Moreover, this might be seen as a new channel via which monetary policy may affect the yield curve in a shadow rate model.

Lastly, $\mathrm{Wu}$ and Xia (2016) provide a measure for the U.K., U.S. and euro area, and construct a comprehensive measure of shadow rates ${ }^{13}$; they also propose a simple analytical representation for bond prices in a multifactor shadow rate term structure model ${ }^{14}$ that can be applied directly to discrete-time data. The novelty in the approach of $\mathrm{Wu}$ and $\mathrm{Xia}$ (2016) lies in their intention to assess the overall effects on the economy and not only on the yield curve. The authors also demonstrate that this model offers an excellent empirical description of the recent behavior of interest rates, as compared to the G-ATSM previously applied in this strand of literature (see Diebold and Rudebusch (2013), among others). Here, the short rate and all other model-implied interest rates cannot go below a minimum rate set as 25 basis points (instead of zero, as in Bauer and Rudebusch, 2015). Moreover, the authors also show a 3-factors Factor-Augmented VAR (FAVAR $)^{15}$ model to study the effects of monetary policy interventions in the case of the U.S. This approach, which is based on a factor structure, allows them to summarize the rich information contained in a large set of economic variables. They extract the first three principal components and then study monetary policy's impact (similar to Lombardi and Zhu, 2014). The computed shadow rates for the U.S. exhibit similar dynamic correlations with macroeconomic variables of interest in the period since July 2009, as did the official rate in data prior to the Great Recession. Furthermore, the authors show that the FED has used unconventional policy measures to successfully lower the shadow rate, and these measures have been more helpful to stimulate the economy (lowering unemployment rate) than a historical version of the Taylor rule.

\subsubsection{Expected Time to Zero and Effective Monetary Stimulus}

There are also alternatives to shadow rates, even if they are linked to them, such as those in Krippner (2014, 2016), which propose the so-called Expected Time to Zero (ETZ) and the Effective Monetary Stimulus (EMS). ${ }^{16}$ The ETZ however, is only defined in unconventional times. The ETZ indicates the future time horizon when the expected path of the short term shadow rates will reach zero, but it does not account for the profile of the policy rate after it becomes positive. Thus, one practical drawback of the ETZ is that it does not provide a quantitative measure of monetary policy in these cases.

As for the "model-based" EMS, this measure is obtained by calculating the total area between the expected path of the short-term shadow rates truncated at zero and the long-horizon nominal natural interest rate (LNIR) proxy (Krippner, 2014, 2016). The EMS is estimated there starting from shadow/lower bound term structure models, but Halberstadt and Krippner (2016) demonstrate that it can also be proxied by a simple combination of observable variables, with the primary component being longer-maturity interest rates (30-year interest rate). Indeed, Halberstadt and Krippner (2016) define it as the area between the lowerbounded nominal forward rate curve and the long-horizon nominal natural interest rate (LNIR), out to a given horizon (in this case 10 years). This latter version is called the "model-free EMS". The LNIR (i.e. surveyed expectations of long-horizon output growth) is built also from an observable variable: using

\footnotetext{
${ }^{13}$ When the ZLB is not binding, the rate is the official overnight interest rate (i.e. EONIA for the euro area).

${ }^{14}$ Previous research has applied the SRTSM to describe the recent behavior of interest rates and monetary policy, such as Kim and Singleton (2012) for Japan and Bauer and Rudebusch (2015) for the U.S. These authors, however, used a simulation-based method. The closest paper to Wu and Xia (2016) in this regard is Krippner (2013b), which proposed a similar version but in a continuous-time setup. This may not be easy to apply in a discrete-time setup. Wu and Xia (2016) hence conclude that their analytical approximation is free of any numerical error associated with simulation methods and numerical integration.

${ }^{15}$ As proposed by Bernanke, Boivin, and Eliasz (2005).

${ }^{16}$ The EMS values are covered in Halberstadt and Krippner (2016) for the euro-area case and in Krippner (2016) for that of the U.S.
} 
Consensus Forecast (CF) survey data. Lastly, the EMS measure differs from the NRR (see Section 5), which is based on short- and medium-horizon estimates in Laubach and Williams (2015).

\section{Our calculation: synthetic index of monetary policy and shadow rates for the euro area}

\subsection{A synthetic index of monetary policy measures for the euro area}

We calculate for the euro area a synthetic index by using Principal Component Analysis, ${ }^{17}$ as also recently done by Bluwstein and Canova (2016) and Kucharčuková et al. (2016). With respect to the latter, however, we add the broadest measure of the nominal effective exchange rate (NEER) instead of EUR/USD (NEER vis-à-vis 42 partners), which in our opinion is a better proxy for the relative openness of the euro area and some foreign factors ${ }^{18}$, EONIA instead of the overnight index swap (OIS), ${ }^{19}$ and main refinancing operations (MRO) as well as having an overall view of the balance sheet contribution. In addition, in the spirit of Bauer and Rudebusch (2015), we have some macroeconomic variables: the HICP rate of change and unemployment rates. ${ }^{20}$ We use monthly series ${ }^{21}$ from 2000M01 to 2016M06 (max) for the aggregate EA19 and we compute an indicator that starts in 2000M01 and ends in 2015M12. ${ }^{22}$ The main sources of data are Eurostat and the ECB statistical data warehouse (SDW). A complete description of variables and sources, together with descriptive statistics, is available in Appendix A.1.

The index is based on a weighted measure of the four components ${ }^{23}$ (weights are the percentages of the overall data variability explained by each factor: $39 \%, 18 \%, 14 \%$ and $9 \%$, which amounts to $80 \%$ of the variability). ${ }^{24}$ This weighted measure is then normalized by using the mean and standard deviation of the 3 month Euro Interbank Offered Rate (Euribor). ${ }^{25}$ The comparison between our components and the 3-month Euribor is reported in the Annex in Fig. 1a and it is comparable to the same figure in Kucharčuková et al. (2016) in Fig. 1b.

\section{[INSERT FIGURES 1a-1b AROUND HERE]}

\footnotetext{
${ }^{17}$ We want to reduce the number of variables while retaining as much of the original variance as possible. We do not impose that the entire variability is explained by our components, leaving space for unobserved factors that we are not able to capture with our variables and can reflect spillovers or other global factors (which, in our case, count for the remaining 20\%).

${ }^{18}$ The U.S. accounted for only 14 per cent of the exports of goods from the EA19 in 2015 and 10 per cent of the imports to EA19 (Source: Eurostat). We are aware that other important trade partners have exchange rate regimes linked to the USD (e.g. China), but not taking into account other situations (for instance other EU members not part of the euro area) would considerably bias, in any case, the contribution of foreign factors and overall openness of the euro area.

${ }^{19}$ This choice is only due to data availability. Since 2012, EONIA has stood at basically zero, and was even negative towards the end of the sample (see Fig. 1c); however, it contributes to the accuracy of the index in the previous periods, as does the Euribor $3 \mathrm{M}$. This choice does not seem to affect the overall outcomes of the factors (see Fig. 1b). The same series is also added in Bluwstein and Canova (2016).

${ }^{20}$ Harmonized unemployment rates, monthly series.

${ }^{21}$ Data are taken as year-on-year change, except for the rates.

${ }^{22}$ We cannot add securities held for monetary policy purposes, because the data start in 2010M06. Kucharčuková et al. (2016) stress that dropping different variables in any case yields robust results. This seems to be the main advantage of this approach as opposed to the yield-curve based factor estimates of Wu and Xia (2016) and Krippner (2014).

${ }^{23}$ The minimum average partial correlation (MAPC) criterion suggests 3 components, while the Kaiser eigenvalue > 1 rule suggests extracting 5 principal components. Lastly, Horn's Parallel Analysis for principal components also suggests 5 components. Kucharčuková et al. (2016) base their choice only on MAPC, and they use 3 factors for their index, although it is based on a principalfactor, and not principal-component, model. If we apply a principal-factor model, the criterion suggests 4 factors. We decided to use 4 components.

${ }^{24}$ Kucharčuková et al. (2016) apply a principal-factor model, and their 3 factors account for almost 100 per cent of the variability.

${ }^{25}$ The normalization as in Kucharčuková et al. (2016) is provided - by firstly subtracting the mean and dividing by the standard deviation of the estimated factors, then multiplying by the standard deviation of the Euribor $3 \mathrm{M}$, and adding the mean
} 
The first component, representing interest rates, can also be seen as a form of the index of euro-area interest rates (Euribor 3M, Euribor 12M, EONIA and euro-area 10-year Government Benchmark bond yield). Thus, it can be interpreted as mainly representing conventional monetary policy measures. The first factor indeed closely follows the policy interest rate of the ECB (Fig. 1a). This first factor, which seems to track mainly conventional measures, is influenced by HICP inflation as well. For a robustness check, we substitute the unemployment rate with the gap in order to perform a sort of Taylor rule (as is also seen in Bauer and Rudebusch, 2015); the results are in line with the baseline outcomes.

The second factor expresses ECB balance sheet measure ${ }^{26}$ and partially the NEER; i.e. it can track unconventional measures. The third one is mainly driven by monetary aggregates, and the fourth is less straightforward to interpret, as it can track both macroeconomic variables and partially balance sheet components. The table with the main factor loadings is reported in the Annex in Table 1.

\section{[INSERT TABLE 1 AROUND HERE]}

This is the reason why our third component performs differently with respect to Kucharčuková et al. (2016). We include a fourth factor in order to capture part of the macroeconomic variability as well. Basically, the more recent data we include (when unconventional measures were in place, in our case the data are until $2016 \mathrm{M}^{2} 6^{27}$ ), less variability is explained by the first factor and more by the second one, which should capture the ECB balance sheet changes.

Thirdly, we compare our index with the EONIA, Euribor 3M and Wu and Xia (2016) shadow rates in Fig.1c. We also performed the same analysis without macroeconomic variables and with EUR/USD. The results are quite robust if we change some variables, as also noted by Kucharčuková et al. (2016); however, the index without macroeconomic variables and NEER seems to less accurately capture the path of the official rate before UMP. In terms of comparison with $\mathrm{Wu}$ and Xia (2016), it is worth recalling that the idea behind our index and that of Kucharčuková et al. (2016) differs from that of the shadow rates, which are constructed from the yield curve. As suggested in Bernanke et al. (2005) and done in $\mathrm{Wu}$ and Xia (2016) for the U.S., it would be worthwhile to calculate an index that is based on principal components with all the measures.

Lastly, we do the same exercise with non-iterated principal factors instead of principal components. In this case, the percentages of the overall data variability explained by each factor are: 47 per cent, 21 per cent, 17 per cent and 15 per cent, which amount to 100 per cent of the variability. The second factor, if iterated, is much noisier than the second component, and this is translated in the index. We report only the non-iterated case. The relative index is in Fig. 1d. This seems to be less able to capture the peak of the Euribor between 2005 and 2008, while the index is, overall, higher afterwards.

\section{[INSERT FIGURES 1c-1d AROUND HERE]}

\subsection{Shadow rates for the euro area}

As we have described in Section 2.3, there are different ways to define shadow rates and empirical approaches. We applied two approaches that were recently proposed in the literature, i.e. Bauer and Rudebusch (2015) and Wu and Xia (2016), to estimate the shadow short rates for the euro area. Both methods are developed in a discrete time setup, thus avoiding numerical integration and its approximation error. Bauer

\footnotetext{
${ }^{26}$ If we compute the index without MRO, the outcome is in line with the reported values. These results are available upon request.

${ }^{27}$ In Kucharčuková et al. (2016), the data are until 2015M07.
} 
and Rudebusch (2015) use a discrete time version of Priebsch's (2013) model, where he proposed to approximate bond prices in the SRTSM using the first two conditional moments of the model. The Wu and Xia (2016) method, on the other hand, approximates forward rates of the SRTSM as the sum of an optionality effect and shadow forward rates. Their method is a discrete time extension of Krippner (2013). For both models, we take the first three principal components of the yield curve as our risk factors. In addition, we vary the lower bound parameter to investigate the robustness of the shadow short-rate estimates.

\subsubsection{Introducing shadow rate term structure models}

GATSMs are designed to extract term premia and future expectations from the yield curve. By imposing linear structure on the yield curve factors, cross-sectional dependence, and linear short rate dynamics, these models can estimate term premia dynamics, which in turn could be used to explain nonstandard monetary policy. When the lower bound is binding, however, these models fit the yield curve data poorly, especially at the lower end of the curve. As a result, most recent research on the term structure of interest rates focuses on non-linear models that constrain the nominal rate to be above zero - the SRTSMs. These models were introduced by Black (1995). Using the 1-factor Vasicek (1977) type of model, Black introduced a theoretical shadow rate that would prevail if there were no physical currency substitute to short term bonds. Such 1-factor models, however, are poor representations of the yield curve, a fact that is welldocumented in Ang and Piazzesi (2003), among many other studies on term structure of interest rates. Nonetheless, SRTSMs with many factors have no closed form solution for bond pricing equations. As a result, numerical methods have been recently suggested to estimate SRTSMs and shadow rates. Here, we focus on two discrete time methods, namely, that of Xia and Wu (2016) and that of Bauer and Rudebusch (2015), by applying them to euro-area yield curve data.

\subsubsection{Description of euro-area yield curve data}

To estimate shadow rates for the euro area, we use yield curve data that are available in the ECB SDW. Daily yield curve data are constructed by first filtering the bond prices in order to ensure that prespecified conditions (e.g. liquidity) are satisfied. The bond prices are then used to estimate daily yield curve parameters, which in turn recover continuous spot, instantaneous forward, and par yield curves. The empirical model for the yield curve is the Svensson (1994) model, which has five parameters that need to be estimated. The loss function is squared distance between actual and model implied yields. The same type of data set was first constructed by Gürkaynak et al. (2007) and is referred to as "GSW data". We use the monthly frequency ECB data starting from 2004M09 until 2016M09.

The main problem in using GSW-type data concerns measurement error due to estimation. Even though yield curves are not estimated precisely, i.e. the measurement error is a few basis points, these curves are used as a basis in empirical term structure literature, such as in Bauer and Rudebusch (2015) and Xia and $\mathrm{Wu}$ (2016), who discuss possible implications on term premia when using GSW data sets. For a 3-factor model, i.e. using three principal components of the curve, the measurement error that is inherited when using GSW artificial yield curve data has a negligible impact on term premia estimates (see Bauer and Rudebusch, 2015). To estimate shadow rates, we use a 3 -factor model, i.e. the first three principal components of the yield curve are the risk factors.

\subsubsection{Shadow rates estimates}

In the Fig. 2, 6 and 7 we show estimated shadow rates for the euro area. It is worth noting that these estimates are not robust to the choice of the lower bound parameter for ECB data. In their original paper, $\mathrm{Wu}$ 
and Xia (2016) set the lower bound to 0.25 for U.S. data, which reflects the FED decision to keep the effective federal funds rate in the range between 0 and 0.25 . For European data, we compute the shadow rate by changing the lower bound from 0 to -0.4 , using the Bauer and Rudebusch (2015) method. ${ }^{28}$ Our computed shadow rates for the euro area are in Fig. 2.

\section{[INSERT FIGURE 2 AROUND HERE]}

The shadow rate level changes greatly, from -6 per cent (lower bound set to -0.4 ) to -2 per cent (lower bound set to 0). In addition, using the same (fixed) lower bounds, we compute different shadow rates with the $\mathrm{Wu}$ and Xia (2016) approach. The results are similar in the sense that the uncertainty surrounding shadow rate estimates is high.

\section{Comparisons and effects on macroeconomic variables}

\subsection{Comparison across methods}

The euro-area spreads á la Baumeister and Benati (2010, 2013) compared to Euribor, are in Fig. 3 in the Annex. The synthetic monetary conditions index (MCI), which was built by principal factor analysis by Kucharčuková et al. (2016), is provided in Fig. 4. For the sake of comparison, a figure in which the main measures of shadow rates (Lombardi and Zhu (2014), Wu and Xia (2016), Krippner (2014)) for the U.S. are summarized is provided in Lombardi and Zhu (2014) and are reported here in the Annex (Fig. 5). Computed shadow rates for the euro area are shown in Fig. 2, and a comparison between the rate by Kortela (2016) and other possible rates are shown in Fig. 6. Wu and Xia (2016) shadow rates for the euro area and the main official interest rate series are shown in the Annex as Fig. 7a. The model-free EMS by Halberstadt and Krippner (2016) for the euro area is reported in Fig. 7b.

\section{[INSERT FIGURES 3-7 AROUND HERE]}

We structured our review starting from the easiest way to design a measure of unconventional monetary policy stance, i.e. spreads, moving to synthetic indices and shadow rates. Every measure has some pros and cons, and in this paragraph we will disentangle the key points in this regard. In Table 2, a summary of the main methodologies is provided with positive aspects and drawbacks of each choice.

\section{[INSERT TABLE 2 AROUND HERE]}

Every method has positive aspects, but there is an evident trade-off between accuracy and manageability. More complete models seem to include aspects relative to the macro-economic effects of UMP, which can better capture all the information coming from these measures. In this regard, synthetic indices and shadow rates may perform better as compared to spreads. Among them, having a rate instead of an index also seems to help the comparability with regular short-term rates in periods of non-ZLB. On the negative side of this approach, they apply the multifactor shadow rate term structure model, which may be complicated to treat and makes it harder to explain to policy makers the economic intuition behind them. Moreover, they may be subject to variation with modelling choices, and these are not an actual interest rates faced by economic agents. It is also good to recall the point by Wu and Xia (2016) in that regard: the common dynamics among different shadow rates point to the same economic conclusion.

\footnotetext{
${ }^{28}$ Lower bound parameters are chosen to match changes in the deposit facility rate during the lower bound period.
} 
Lombardi and Zhu (2016) offer an interesting half-way solution. They use a shadow rate series from a dynamic factor model with missing observations to extract common components from a large set of variables. $\mathrm{Wu}$ and Xia (2016) provide a similar rate, and they demonstrate that it is very much comparable to their measure of shadow rate from a multifactor shadow rate term structure model used in Bauer and Rudebusch (2015), Lemke and Vladu (2015) and Kortela (2016).

Lastly for the EMS, we consider the model-based measure such as is found in Krippner $(2014,2016)$ while it is more robust and less subject to variation with modelling choices compared to shadow rates, it may be complicated to reproduce and to provide with an economic intuition. Moreover, it is in continuous-time, and may be not easy to apply in a discrete-time setup. As for the model-free EMS found in Halberstadt and Krippner (2016), the use of only observable variables is the main advantage of the method. ${ }^{29}$ Again, unlike shadow rates, this is more consistent and comparable across conventional and unconventional monetary policy environments, and is less subject to variation with estimation methods. A main disadvantage of this approach is, however, that even if this EMS is quite robust, it is dependent on the proxy used for the LNIR and on CF surveys. In any case, Halberstadt and Krippner (2016) conclude that the model-free EMS and their modelbased EMS con-move very tightly, and therefore the model-estimated interest rate is very close to the observed interest rate. In addition, the model-based EMS has an advantage over the model-free EMS in that it allows the decomposition of the EMS into expected policy and risk premium components.

\subsection{Effect of measures on inflation and on other macroeconomic variables}

The impact of these UMP measures to analyze monetary policy shocks is reported in Table 3 . Inflation rates seem to persistently react to the UMP shock significantly, more so than in the case of conventional measures and more quickly using a synthetic index (Kucharčuková et al., 2014; Bluwstein and Canova, 2016). For the euro area, this is especially true if the indirect effect coming from U.S. monetary policy actions is taken into account (Comunale and Kunovac, 2017; using shadow rates).

Indeed the shadow rates computed by $\mathrm{Wu}$ and $\mathrm{Xia}$ (2016) recently have been used by Comunale and Kunovac (2017) to identify a relative monetary policy shock in a Bayesian VAR setup that analyzes HICP and import price inflation in the euro area. The period considered there includes the ZLB, and the rates are taken as the difference between the euro-area and the U.S. rates. For consumer prices, a positive shock in euro-area monetary policy decreases inflation by 0.10 per cent, while the relative shock implies a 0.20 per cent decrease. The authors conclude that decisions coming from the U.S. on conventional and unconventional monetary policy also matter for the inflation dynamics in the euro area. ${ }^{30}$

Halberstadt and Krippner (2016) provide an analysis based on a small-scale monetary TVP-VAR for the euro area by using their EMS measures to capture monetary policy stance. ${ }^{31}$ Their results indicate that the euro-area monetary policy has helped to keep inflation and economic activity higher than they might have been otherwise.

\footnotetext{
${ }^{29}$ More specifically, it combines the expected average real output growth and inflation for the 6-10 year horizon into a nominal output growth result.

${ }^{30}$ The paper also looks at how this shock, among others, may move both inflation and the exchange rates in the first place. This ratio can be seen as a more accurate measure of the Exchange Rate Pass-Through (ERPT) driven by different shocks. The relative monetary policy shock is indeed the predominant one for the ratio with consumer prices, together with the exogenous exchange rate shock itself and the positive effect of aggregate demand. The impact is smaller if the shadow rate is not taken in relative terms.

${ }^{31}$ These models require at least a monetary policy variable together with a measure of deviations of output gap, and a measure of inflation.
} 
A recent paper by the ECB (2017) also found a positive contribution of UMP shocks ${ }^{32}$ over the first three quarters of 2015. Nonetheless, it is crucial to look at the channels through which this may happen. The paper studied two such channels: the expectation or re-anchoring channel, and the exchange rate pass-through channel. Concerning the former, which is related to balance sheet measures, this paper stressed that balance sheet expansion can help to curtail mounting risks of de-anchoring. ${ }^{33}$ For the second channel, this study argues that the exchange rate channel is rather strong when moved by monetary policy shocks and even stronger when the exchange rate is moved by conventional monetary policy shocks.

\section{[INSERT TABLE 3 AROUND HERE]}

Concerning the effect of UMP on GDP growth and unemployment, the literature is even less extensive. The key outcome of the analysis by Baumeister and Benati $(2010,2013)$ is that across countries analyzed in the paper, a decrease in the long-term yield spread (1\% negative shock) exerts a powerful effect on both output growth and inflation. Wu and Xia (2016) show that the FED has used unconventional policy measures to successfully lower the shadow rate, and that these measures have better stimulated the economy (i.e. by lowering the unemployment rate) than a historical version of the Taylor rule.

\subsection{Other approaches to identify unconventional measures to analyze inflation}

Several other studies analyze determinants and dynamics of low inflation in a period of ZLB, especially focused on the euro area, with different measures to identify monetary policy shocks in a ZLB context. Some of these papers use the EONIA rate to identify monetary policy shocks, and it can be useful to compare them with the above-mentioned studies. The VAR approach is widely used here as well, both in a classic approach and in a Bayesian one. For instance, recently Conti et al. (2015) looked at the structural shocks affecting inflation in the euro area, identifying shocks in a Bayesian VAR with sign restrictions for the period of 1995Q1-2014Q4. The authors used sign restrictions to quantify the contribution of oil supply, aggregate demand, and monetary policy shocks. It was found that a positive monetary shock leads to a persistent decline in output and inflation, and to an immediate appreciation of the euro. The increase in the short-term rate reduces oil prices and causes a moderate decline of world demand for euro-area goods and services. This paper also computed the historical decomposition of annual HICP inflation, finding that in 2013-2014 the main drivers of low inflation were the aggregate demand and oil prices, with a very minor role played by monetary policy. In this case, however, the monetary policy shock is identified by the use of the regular short-term interest rates (EONIA). This shock impacts positively on this rate (positive monetary policy shock) and exchange rate, while bringing down inflation and output. Conti et al. do not explicitly consider UMP and refer to Peersman (2011) who claims that the adoption of the EONIA as the policy rate somewhat captures the additional easing induced by the excess liquidity generated by the ECB unconventional measures. ${ }^{34}$ Importantly, however, Peersman (2011) does not cover the recent period in which ECB uses UMP measures (1999M01-2009M12), while Conti et al. (2015) use data until the end of 2014.

\footnotetext{
${ }^{32}$ The UMP shock was identified by restrictions on the spread between long- and short-term rates à la Baumeister and Benati (2013), as explained in Section 2, where with short-term rates at zero, a decrease in the long-term rate (and hence in the spread) is expansionary.

${ }^{33}$ The de-anchoring might explain the failure of inflation in the euro area to track the recovery in the real economy, especially after a prolonged period of adverse shocks.

${ }^{34}$ Peersman (2011) mainly provides a setup in which the policy rate in the VAR is the minimum bid rate of variable rate tenders or the rate applied to fixed rate tenders in the MROs. There the author labels all policy measures that affect the supply of credit beyond the policy rate as "unconventional" or "non-standard". The results of using EONIA are in the robustness checks.
} 


\section{The Natural (Real) Rate of Interest}

A new strand of literature has proposed an alternative to the above-mentioned measures, which are linked to interest rates for policy purposes. The new idea is not to measure a rate or index to count for the period of ZLB, but to assess the accuracy of conventional policy and to understand for how long unconventional measures may be needed. The length and impact of UMP can be studied by looking at the NRR of interest, as a measure of the equilibrium rate, keeping in mind that different approaches may give different rates (Brand, 2016). These natural rates may be useful for determining whether interest rates will remain as low as they have been since 2008, as pointed out in Laubach and Williams (2015), if properly modelled and estimated. In case of negative NRR, the episodes in which short-term interest rates would be constrained from below would become more frequent and long-lasting, and unconventional policy tools may continue to play an important role in the future.

The NRR may be seen as a guidepost to whether conventional policy is too tight or too loose (Lubik and Matthes, 2015). This assumes that short-term rates above NRR are expected to lower inflation, whereas those below are expected to raise inflation. Looking at whether they will remain as low as in recent years (Laubach and Williams, 2015; Pedersen, 2015) and at the role of trends in the NRR (Laubach and Williams, 2015; Brand, 2016) is, of course, crucial. The NRR is strictly linked to the idea of secular stagnation (Summers, 2014a, b): negative output gap and too-low NRR to be reached by an actual rate (i.e. negative NRR in case of ZLB) make conventional monetary policy ineffective (Pedersen, 2015). The main policy implications involve UMP, which can become the only possible instrument, and also can justify a major role for fiscal policies and structural reforms (to increase natural output).

There are different ways to define and model a "Natural Real Rate of Interest", as recently reported by Laubach and Williams (2015). The main frameworks with some economic structure ${ }^{35}$ found in the literature are: 1) a fully structural dynamic stochastic general equilibrium (DSGE) model; and 2) a semi-structural model with the use of filtering techniques, mainly Kalman filtering, as in Laubach and Williams (2003). The natural rate has been taken as the real interest rate that would prevail if all prices were flexible and the longrun value of the rate is kept constant. The latter approach has been applied in recent analysis using DSGE models (Curdia et al., 2015 for the U.S. and Goldby et al., 2015 for the U.K.). ${ }^{36}$ The results of these studies are in line with the ones following the Laubach and Williams (2003) model: there has been a large decline in the NRR especially since the crisis.

Laubach and Williams (2015), for their part, use the short-term values of rates in order to achieve a long-run perspective, and define the NRR as the real short-term interest rate consistent with the economy operating at its full potential once transitory shocks to aggregate supply or demand have abated. In this way, they abstract the rate after the economy has emerged from any cyclical fluctuations and is expanding at its trend rate. More generally, as reported by Cukierman (2016b), the natural rate is the real rate at which the output gap (and, therefore, inflation) is equal to zero (or more generally, equal to the inflation target) in the absence of temporary shocks. Since both the natural rate and the output gap are unobservable, they have to be inferred from observable variables.

Concerning the methods to actually calculate such a rate, in the domain of semi-structural models, all univariate approaches have been shown to have major drawbacks. Laubach and Williams (2015) thus apply a multivariate model that incorporates movements in inflation, output, and interest rates and use multivariate

\footnotetext{
${ }^{35}$ Other methods include filtering the series, cointegrated methods, and VAR models (see Weber (2006) for a general discussion, Hamilton et al. (2016) for cointegrated methods, and Lubik and Matthes (2015) for a Time-Varying Parameter VAR).

${ }^{36}$ There are several differences between the DSGE approach and a model $a ́$ la Laubach and Williams. In a DSGE framework, the NRR is defined as the rate that achieves price stability period-by-period (Laubach and Williams: allow for shocks that have transitory effects on the output gap and inflation) and NRR as the stationary linear combination of transitory shocks to preferences and technology (Laubach and Williams allow for the natural rate to be affected by low-frequency nonstationary processes).
} 
Kalman filter estimates. The baseline is the Laubach and Williams (2003) model. There, the NRR is implicitly defined by the absence of inflationary or deflationary pressures. The natural rate is assumed to depend on the estimated contemporaneous trend growth rate of potential output and a time-varying unobserved component (assumed to follow a random walk process) that captures the effects of other unspecified influences on the natural rate. The model is estimated using the Kalman filter: the estimates of the unobserved variables - the NRR, the level of potential output, and its trend growth rate - should be partially adjusted based on the distance between the model's predictions for real GDP and inflation and the actual outcomes. ${ }^{37}$

These estimates of the NRR display two periods of significant declines: a moderate secular decline over the two decades preceding the Great Recession, and a second, more substantial decline during the Great Recession (Williams, 2015). As explained in Laubach and Williams (2015), this means that the Kalman filter interprets this combination of fairly low GDP growth and negative real interest rates as indicating a very low level of the NRR. Even with the economy mostly recovered from the recession, there is no sign of a rebound in the NRR. However, the baseline Laubach and Williams (2003) model assumes that the recent decline in the natural rate is permanent. In the extended Laubach and Williams (2015), the authors try to relax this assumption.

The NRRs for the U.S., based on this paper and updated to 2016Q1, are available in the Annex in Fig. 8. A complete comparison between the Xu and Xia (2016) shadow rates, Laubach and Williams (2015) NRR, and official short-term rates for the U.S. is provided in Fig. 9.

\section{[INSERT FIGURES 8-9 AROUND HERE]}

An alternative to Laubach and Williams (2003), with fewer restrictions, is provided by Lubik and Matthes (2015). These authors apply a Time-Varying Parameter VAR (TVP-VAR) ${ }^{38}$ and draw a comparison between the two methods (reported in the Annex, Fig.10). However, the key outcome is the same: since 2008, there has been a substantial and unprecedented decline in the NRR.

\section{[INSERT FIGURE 10 AROUND HERE]}

Previous research addressed the euro-area NRR by using the method found in Laubach and Williams (2003): Mésonnier and Renne (2004) (data for 1979Q1-2002Q4), Garnier and Wilhelmsen (2005) (data for 1963Q1-2004Q1) and Benati and Vitale (2007) (data for 1970Q1-2006Q4). Garnier and Wilhelmsen (2005) find a decline in the natural rate over the past 40 years for the euro area as well. Furthermore, they show that the real rate gap may contain valuable information about future inflation, bearing in mind the uncertainty in the estimates. This is in line with Mésonnier and Renne (2004), who find a non-significant interest rate gap after 1999 that may indicate that monetary policy has been broadly appropriate since then in terms of stabilizing inflation. Finally, Benati and Vitale (2007) confirm the decline in the most recent quarters and also that the natural rate estimates have historically been characterized by a significant degree of uncertainty. This last paper, however, does not impose any correlation whatsoever between the natural rate and trend output growth, and it clearly still finds a close co-movement between these variables.

\footnotetext{
${ }^{37}$ This means that for a given estimate of the potential output (or gap), the model forms a prediction for this variable next period. The output gap estimate in turn is informed by an estimated Phillips curve that correlates core inflation to its own lags, the lagged output gap, and movements in the relative prices of oil and non-energy imports. If inflation turns out lower than predicted by the existing estimates for potential output, the level of potential output is revised up (that is, the output gap is revised down), with most of this revision assigned to the level of potential GDP, and a relatively small fraction assigned to the trend growth rate.

${ }^{38}$ Laubach and Williams (2003) assume economic relationships between the key macroeconomic variables; while Lubik and Matthes (2015) stress that a TVP-VAR is largely agnostic on this dimension. It simply captures the co-movement between these variables in a flexible manner.
} 
More recently, Belke and Klose (2016) described the NRR for some individual euro-area member countries (eleven old euro-area members and Greece) by applying the setup in Laubach and Williams (2003); Holston et al. (2016) provide the NRR for the U.S., Canada, U.K. and the euro area by using the same approach. In the first contribution, the authors conclude that indeed the NRR has been falling since the 1990s and in the crisis period it dropped to -2 per cent at its lower bound ${ }^{39}$, with the notable exception of Greece, where it is estimated at -10 per cent (see Fig.11). In the latter case, the authors conclude that the NRR is indeed too low with respect to the actual rate, and that this may be a sign of secular stagnation. Holston et al. (2016) find a co-movement in NRRs for the four considered economies, and confirm the decline in the NRR in the last decades (see Fig. 12a, b in the Annex for the euro area and the U.S., respectively). This seems to suggest that global factors play an important role in trend growth and real interest rates. The NRR itself is in large measure explained in this model by a significant decline in the estimated trend growth rates found in all four economies, together with other highly persistent factors, including some global ones. The authors do not find that the natural rates are increasing in the most recent periods. Again, it is stressed here that the estimates of NRRs are highly imprecise, and those for Canada, the U.K. and the euro area are more imprecise than those for the U.S.

Pedersen (2015) modifies the baseline Laubach and Williams model to fit the situation in Denmark. The author introduces the open-economy dimension of Berger and Kempa (2014) and, in light of smallsample and unit-root issues, estimates the model by Bayesian methods. In this case as well, the main conclusion follows the rest of the literature: we have experienced very low NRR since the crisis and its trend is negative (may stay low for 5-10 years). However, Pedersen (2015) and Berger and Kempa (2014) note that cyclical factors matter, and an adjustment has to be made in the medium-run.

The most recent contribution for the euro area was made by Fries et al. (2016), as illustrated in Fig.13. The authors applies the framework á la Laubach and Williams (2003) and jointly estimate the time-varying national natural real rates of interest for the largest four economies (DE, FR, ES and IT) of the euro area over the period 1999-2016. They find evidence of an increased dispersion of NRRs across major economies during the sovereign debt crisis. This dispersion, they argue, translated into a quite restrictive monetary policy stance in Southern economies, notably in Spain, while the policy stance remained neutral or slightly accommodative in core countries. ${ }^{40}$

\section{[INSERT FIGURES 11-13 AROUND HERE]}

Taylor and Wieland (2016) offer several criticisms of the above-mentioned NRR approach. They conclude that the estimates of time-varying real equilibrium interest rates, emerging from recent research, are not yet useful for application to current monetary policy. They also show that the estimates are subject to the omitted variable or even omitted equation bias, and that the results are not robust if alternative specifications are applied. Ultimately, the evidence pointing to a recent decline in NRR may have been generated by some omitted regulatory and policy variables. ${ }^{41}$ In this regard, Brand (2016) also notes the prevalent downward trend in such estimates, but also that the measures fluctuated and diverged greatly. He attributes this last finding to the difficulties in small samples of simultaneous disentangling of idiosyncratic shocks to permanent and transitory components in the real interest rate and output.

\footnotetext{
${ }^{39}$ The main aim of the paper is to determine if euro-area countries have been facing a form of secular stagnation since 2008 .

${ }^{40}$ We thank Andrea Gerali and Andra Smadu for suggesting this paper for our review.

${ }^{41}$ Notably, Laubach and Williams (2015) added shifts in output gap to their estimations.
} 
Cukierman (2016a, b) argues that long-term risky rates are more important determinants of the output gap and inflation than the short-term policy rate. Therefore, he is prefers a so-called "risky natural rate of interest". ${ }^{42}$ Recognition of the role of risk may allow for a more direct link between the health of the financial system and potential output. Yet, almost all existing estimates of the natural rate refer to riskless rates (Laubach and Williams, 2015 and Curdia et al., 2015).

A recent improvement noted in the literature concerns the role of financial variables and cycles in modelling the NRR. Indeed, potential output and symptoms of unsustainability, as well as financial factors, need to be taken into account. Output cannot be at a sustainable level if the financial side of the economy is misaligned. A possible way to cope with the issue is a "finance-neutral" NRR, recently proposed by Juselius et al. (2016). The results for the U.S. are shown in Fig. 14. They indeed use a filtering system that allows financial factors to play a role in business fluctuations, and then jointly estimate the "finance neutral" NRR and potential output. The differences between the Juselius et al. (2016) NRR and the regular Laubach and Williams (2015) estimates are evident. Moreover, the authors also propose a monetary policy rule that systematically takes into account the state of the financial cycle, which may be of help in the discussion started by Yellen (2015) and Taylor and Wieland (2016) on the possible role of NRR within an adjusted Taylor-rule. ${ }^{43}$

\section{[INSERT FIGURE 14 AROUND HERE]}

Ultimately, Pescatori and Turunen $(2015)^{44}$ in a Bayesian setup explicitly account for additional monetary policy accommodation through unconventional policies by using shadow policy rates in the case of the U.S. Hence, the gap between actual shadow rates and the NRR can also be used to assess unconventional measures. In addition, they find a decline in recent NRR (and they expect a slow increase in the medium-run) and an increasing role for global factors (i.e. excess global savings in their case). The comparison for the U.S. between the regular NRR á la Laubach and Williams (2015) and their measure based on shadow rates is provided in Fig. 15.

\section{[INSERT FIGURE 15 AROUND HERE]}

However, they also point out that, based on their assessment, monetary policy has been strongly accommodative, especially when unconventional monetary policy is considered. Re-estimating the model with shadow rates seems to suggest an even lower NRR, but given the larger implied interest rate gaps, more policy accommodation as well.

To summarize, the main open questions about NRR concern modelling and the information we can actually use for policy-making. If we want to use a Laubach and Williams-type model, there is still room for improvement:

\footnotetext{
${ }^{42}$ This idea is also supported by empirical findings in Gilchrist and Zakrajsek (2012), where an index of interest rate spreads, between risky corporate bonds and riskless U.S. Treasury bonds, is reported. They show that this index possesses a substantial predictive ability for future economic activity.

${ }^{43}$ See also Stasiukynaite (2017) for a deeper analysis of monetary policy stance and policy rules with NRR. A summary of policy issues and a NRR-augmented Taylor rule for the euro area can be also found in Claeys (2016). The latter claims that in the euro area a modified Taylor rule has called for a negative policy rate since the end of 2012, and that the current level of ECB rates and additional unconventional policies to push the yield curve lower seem to be justified.

${ }^{44}$ The shadow rates are also accounted for in Johannsen and Mertens (2016), albeit in a different setup (i.e. a dynamic time-series model). This model sees less movement in the trend real interest rate over the past decade than in the results reported in some other studies, such as Laubach and Williams (2015).
} 
i) introducing an explicit role for global factors and co-movements (and spillovers/interactions), as stressed by Pedersen (2015) and Holston et al. (2016);

ii) adding demographics (Gagnon et al., 2016; Carvalho et al., 2016); ${ }^{45}$

iii) allowing real effective exchange rate (REER) equilibria to be modelled by using real/financial determinants of REERs themselves (Lane and Milesi-Ferretti, 2004; Comunale, 2015; 2017) instead of having a REER equilibrium as a random walk, as in Berger and Kempa (2014) and Pedersen (2015);

iv) recognizing a role for risk (Brand, 2016; Cukierman, 2016);

v) properly modelling the euro area as a whole or a small open economy (Pedersen, 2015); and

vi) having a framework that includes unconventional monetary policy actions (Pescatori and Turunen, 2015).

Concerning the usefulness of NRR for policy recommendations, it is worth stressing that, as pointed out by Pedersen (2015), low NRR may have a key impact in fueling asset prices, and can cause financial stability issues. The use of NRR can be also extended to a macro-prudential policy assessment, if properly modelled.

\section{Conclusions}

We reviewed the literature on alternative monetary policy indicators in the period when the zero lower bound is binding, and we applied several methodologies to euro-area data. We did not find any single indicator that stood out as the best from the pool that the literature suggests. Spread indicators fail to capture many important features, as their information set is limited. The synthetic index, computed through principal component analysis, either lacks economic interpretation or cannot be compared directly to policy interest rates. The third indicator, namely, the shadow short rate, is consistent with the term structure of interest rates and is comparable to policy rates, but it is prone to large model uncertainty. The last option related to the shadow rates is the model-free EMS (Halberstadt and Krippner, 2016). It has the advantage of being based only on observable data, even if it may depend on proxies used in the model.

Generally speaking, across studies and methods, the impact on inflation of UMP shocks is found to be positive. It is also worth stressing the importance of different channels through which the UMP measures may impact inflation, with particular focus on expectation and exchange rate pass-through. Some results also favor a positive effect of UMP on output and unemployment (Baumeister and Benati, 2010; 2013 and Wu and Xia, 2016)

Finally, we provide an overview of the NRR, as the resulting interest rate gap may serve as a valuable tool in assessing monetary policy stance. However, its use involves some drawbacks, particularly its lack of robustness. In that regard, we propose a list of possible ways to improve such estimates.

\footnotetext{
${ }^{45}$ These findings are based on an overlapping generation model (in case of Gagnon et al., 2016) or on a tractable life-cycle model (Carvalho et al., 2016).
} 


\section{REFERENCES}

Andrés, J., López-Salido, J. D., \& Nelson, E. (2009). Money and the natural rate of interest: Structural estimates for the United States and the euro area. Journal of Economic Dynamics and Control, 33(3), 758-776.

Ang, A., \& Piazzesi, M. (2003). A no-arbitrage vector autoregression of term structure dynamics with macroeconomic and latent variables. Journal of Monetary Economics, 50(4), 745-787.

Bauer, M. D., \& Rudebusch G. D. (2015). Monetary Policy Expectations at the Zero Lower Bound. Federal Reserve Bank of San Francisco, Working Paper.

Baumeister, C. \& Benati, L. (2010). Unconventional monetary policy and the great recession - Estimating the impact of a compression in the yield spread at the zero lower bound". No 1258, Working Paper Series, European Central Bank.

Baumeister, C. \& Benati, L. (2013). Unconventional Monetary Policy and the Great Recession: Estimating the Macroeconomic Effects of a Spread Compression at the Zero Lower Bound. International Journal of Central Banking, 9(2), 165-212.

Belke, A. \& Klose, J. (2016). Equilibrium Real Interest Rates and Secular Stagnation - An Empirical Analysis for Euro Area Member Countries. Ruhr Economic Papers, No 621.

Benati, L. \& Vitale, G. (2007). Joint estimation of the natural rate of interest, the natural rate of unemployment, expected inflation, and potential output. Working Paper Series, No 0797, European Central Bank.

Berger, T. \& Kempa, B. (2014). Time-varying equilibrium rates in small open economies: Evidence for Canada. Journal of Macroeconomics 39, 203-214.

Bernanke, B., Boivin, J., \& Eliasz, P. (2005). Factor augmented vector autoregressions (FVARs) and the analysis of monetary policy. Quarterly Journal of Economics, 120(1), 387-422.

Black, F. (1995, November/December). Interest rates as options. Journal of Finance, 50(5), 1371-1376.

Blinder, A. (2010). Quantitative easing: entrance and exit strategies. Federal Reserve Bank of St. Louis Review.

Blinder, A. (2012, February). Revisiting monetary policy in a low inflation and low utilization environment. Journal of Money, Credit and Banking.

Bluwstein, K., \& Canova, F. (2016, September). Beggar-thy-neighbor? The international effects of ECB unconventional monetary policy measures. International Journal of Central Banking.

Bobeica, E. \& Jarocinski, M. (2017). Missing disinflation and missing inflation: the puzzles that aren't. Working Paper Series, European Central Bank, No 2000 / January 2017.

Brand, C. (2016). Challenges in modelling the natural rate of interest. Mimeo.

Carvalho, C., Ferrero, A. \& Nechio, F. (2016). Demographics and real interest rates: inspecting the mechanism. Working Paper Series 2016-5, Federal Reserve Bank of San Francisco.

Chen, Q., Filardo, A., He, D., \& Zhu, F. (2015). Financial crisis, US unconventional monetary policy and international spillovers. BIS Working Papers 494, Bank for International Settlements.

Claeys, G. (2016). Low long-term rates: bond bubble or symptom of secular stagnation? Policy Contribution Issue No15, Bruegel.

Comunale, M. \& Kunovac, D. (2017). Exchange rate pass-through in the euro area. Working Paper Series, European Central Bank, No.2003/2017

Comunale, M. (2015). Long-Run Determinants and Misalignments of the Real Effective Exchange Rate in the EU. Bank of Lithuania. Working Paper Series No 18/2015.

Comunale, M. (2017). Dutch Disease, Real Effective Exchange Rate Misalignments and their effect on GDP Growth in the EU, Journal of International Money and Finance, Volume 73, Part B, May 2017, Pages 350-370. 
Conti, A. M., Neri, S., \& Nobili, A. (2015). Why is inflation so low in the euro area?, Temi di discussione (Economic working papers) 1019, Bank of Italy, Economic Research and International Relations Area.

Cukierman, A. (2016a). Reflections on the natural rate of interest, its measurement, monetary policy and the zero lower bound. CEPR, DP 11467; also published in E Gnan and D Masciandaro (eds), Central banking and monetary policy: What will be the post-crisis new-normal?, SUERF Conference Proceedings 2016/4, Larcier.

Cukierman, A. (2016b). Reflections on the natural rate of interest, its measurement, monetary policy and the zero lower bound. VoxEU 15 October 2016, http://voxeu.org/article/natural-rate-interest-itsmeasurement-monetary-policy-and-zero-lower-bound

Cúrdia, V., Ferrero A., Ng, G.C. \& Tambalotti, A. (2015). Has U.S. Monetary Policy Tracked the Efficient Interest Rate? Journal of Monetary Economics, 70, 72-83.

Diebold, Francis X., and Glenn D. Rudebusch. (2013). Yield Curve Modeling and Forecasting. Princeton, NJ: Princeton University Press.

European Central Bank. (2017). Low inflation in the euro area: causes and consequences. Occasional Paper Series, No 181 / January 2017.

Fries, S., Mésonnier, J.S., Mouabbi, S. and Renne, J.P. (2016). National natural rates of interest and the single monetary policy in the Euro Area. Banque de France, Working Paper Series no. 611.

Gagnon, E., Johannsen, B. K. \& Lopez-Salido, J. D. (2015). Understanding the New Normal: The Role of Demographics (2016-09-28). FEDS Working Paper No 2016-080.

Garnier, J. \& Wilhelmsen, B.-R. (2005). The natural real interest rate and the output gap in the euro area: a joint estimation. Working Paper Series 0546, European Central Bank.

Gilchrist, S. \& Zakrajšek, E. (2012). Credit spreads and business cycle fluctuations. American Economic Review, 102(4): 1692-1720.

Goldby, M., Laureys, L. \& Reinold, K. (2015, August 11). An estimate of the UK's natural rate of interest. Bank Underground (Bank of England blog). http://bankunderground.co.uk/2015/08/11/an-estimate-ofthe-uks-natural-rate-of-interest/

Gürkaynak, R. S., Sack, B., \& Wright, J. H. (2007). The US Treasury yield curve: 1961 to the present. Journal of monetary Economics, 54(8), 2291-2304.

Halberstadt, A. \& Krippner, L. (2016). The effect of conventional and unconventional euro area monetary policy on macroeconomic variables. No 49/2016, Discussion Papers from Deutsche Bundesbank, Research Centre.

Hamilton, J.D., Harris, E.S., Hatzius, J. and West, K.D. (2016). The Equilibrium Real Funds Rate: Past, Present, and Future, IMF Economic Review, Palgrave Macmillan; International Monetary Fund, vol. 64(4), pages 660-707, November.Holston, K., Laubach, T., \& Williams, J.C. (2016). Measuring the Natural Rate of Interest: International Trends and Determinants. Federal Reserve Bank of San Francisco Working Paper 2016-11.

Johannsen, B.K. \& Mertens, E. (2016). The Expected Real Interest Rate in the Long Run: Time Series Evidence with the Effective Lower Bound. FEDS Notes. Washington: Board of Governors of the Federal Reserve System, February 9, http://dx.doi.org/10.17016/2380-7172.1703

Juselius,M., Borio,C., Disyatat, P. \& Drehmann, M. (2016, July 2016). Monetary policy, the financial cycle and ultra-low interest rates. BIS Working Papers No 569.

Kim, Don H., \& K. J. Singleton. (2012). Term Structure Models and the Zero Bound: An Empirical Investigation of Japanese Yields. Journal of Econometrics, 170, 32-49.

Kortela, T. (2016). A Shadow rate model with time varying lower bound of interest rates. Bank of Finland Research Discussion Paper No 19/2016. 
Krippner, L. (2013a). Measuring the stance of monetary policy in zero lower bound environments. Economics Letters, 118(1), 135-138.

Krippner, L. (2013b). A Tractable Framework for Zero Lower Bound Gaussian Term Structure Models. Australian National University, CAMA Working Paper 49/2013.

Krippner, L. (2014). Measuring the stance of monetary policy in conventional and unconventional environments. Australian National University CAMA Working Paper 6/2014.

Krippner, L. (2016). Documentation for measures of monetary policy. New Zealand's central bank, mimeo.

Kucharčuková, O. B., Claeys, P. \& Vašíček, B. (2016, March-April). Spillover of the ECB's Monetary Policy Outside the Euro Area: How Different is Conventional From Unconventional Policy? Journal of Policy Modeling, 38(2), 199-225.

Lane, P. R., \& Milesi-Ferretti, G. M. (2004). The transfer problem revisited: Net foreign assets and real exchange rates. Review of Economics and Statistics, 86(4), 841-857.

Laubach, T., \& Williams, J.C. (2003, Measuring the Natural Rate of Interest. The Review of Economics and Statistics, 85(4), 1063-1070.

Laubach, T. \& Williams, J.C. (2015). Measuring the Natural Rate of Interest Redux. Federal Reserve Bank of San Francisco Working Paper 2015-16.

Lemke, W. \& Vladu, A. (2015). A Shadow-Rate Term Structure Model for the Euro Area. Annual Conference 2015 (Muenster): Economic Development - Theory and Policy 113159, Verein für Socialpolitik / German Economic Association.

Lemke, W. \& Vladu, A. (2016). Below the zero lower bound: a shadow-rate term structure model for the euro area. Working Paper, European Central Bank, No 1991

Lombardi, M. \& Zhu, F. (2014). A shadow policy rate to calibrate US monetary policy at the zero lower bound, Working Paper, BIS, No 452.

Lubik, T. A., and Matthes, C. (2015). Calculating the Natural Rate of Interest: A Comparison of Two Alternative Approaches. Federal Reserve Bank of Richmond Economic Brief, October 2015, EB1510.

Mésonnier, J-S. \& Renne, J-P. (2004). A Time-Varying Natural Rate for the Euro Area. Working Papers 115, Banque de France.

Pattipeilohy, C., Van Den End, J. W., Tabbae, M., Frost, J., \& De Haan, J. (2013). Unconventional monetary policy of the ECB during the financial crisis: An assessment and new evidence. DNB Working Paper series, No 381/2013.

Pedersen, J. (2015). The Danish Natural Real Rate of Interest and Secular Stagnation. Working Paper, No 94, 2015, Danmarks Nationalbank.

Peersman, G. (2011). Macroeconomic Effects of Unconventional Monetary Policy in the Euro Area. No 1397, Working Paper Series, European Central Bank.

Pesaran, M. H., Schuermann, T., \& Weiner, S. M. (2004). Modeling regional interdependencies using a global error-correcting macroeconometric model. Journal of Business \& Economic Statistics, 22(2), 129162.

Pescatori, A. \& Turunen, J. (2015). Lower for Longer: Neutral Rates in the United States. IMF WP series $\mathrm{WP} / 15 / 135$.

Priebsch, Marcel A. (2013). Computing Arbitrage-Free Yields in Multi-Factor Gaussian ShadowRate Term Structure Models. Finance and Economics Discussion Series, Federal Reserve Board.

Stasiukynaite, R. (2017). Understanding monetary policy stance. Bank of Lithuania, Occasional Paper Series, No.14/2017.

Summers, L. H. (2014a). Reflections on the New Secular Stagnation Hypothesis. In Secular Stagnation: Facts, Causes and Cures, Chapter 1, pp. 27-38. VoxEU.org. 
Summers, L. H. (2014b). US economic prospects: Secular stagnation, hysteresis, and the zero lower bound. Business Economics 49(2), 65-73.

Svensson, L. E. (1994). Estimating and Interpreting Forward Interest Rates: Sweden 1992-1994. Centre for Economic Policy Research, Discussion Paper No 1051.

Taylor, J. B. \& Wieland, V. (2016). Finding the Equilibrium Real Interest Rate in a Fog of Policy Deviations, CEPR Discussion Papers 11264, C.E.P.R. Discussion Papers.

Vasicek, O. (1977). An equilibrium characterization of the term structure. Journal of financial economics, $5(2), 177-188$.

Weber, A.A. (2006). The role of interest rates in theory and practice - How useful is the concept of the natural real rate of interest for monetary policy?, G.L.S. Shackle Memorial Lecture 2006.

Williams, J. C. (2015, April). The Decline in the Natural Rate of Interest. Business Economics, 50(2), 57-60.

Wu J.C. \& Xia F.D. (2016). Measuring the Macroeconomic Impact of Monetary Policy at the Zero Lower Bound. Journal of Money, Credit, and Banking, 2016, 48(2-3), 253-291. 


\section{ANNEX: Tables and Figures}

Figure 1a: 4 principal components v. EURIBOR 3 months

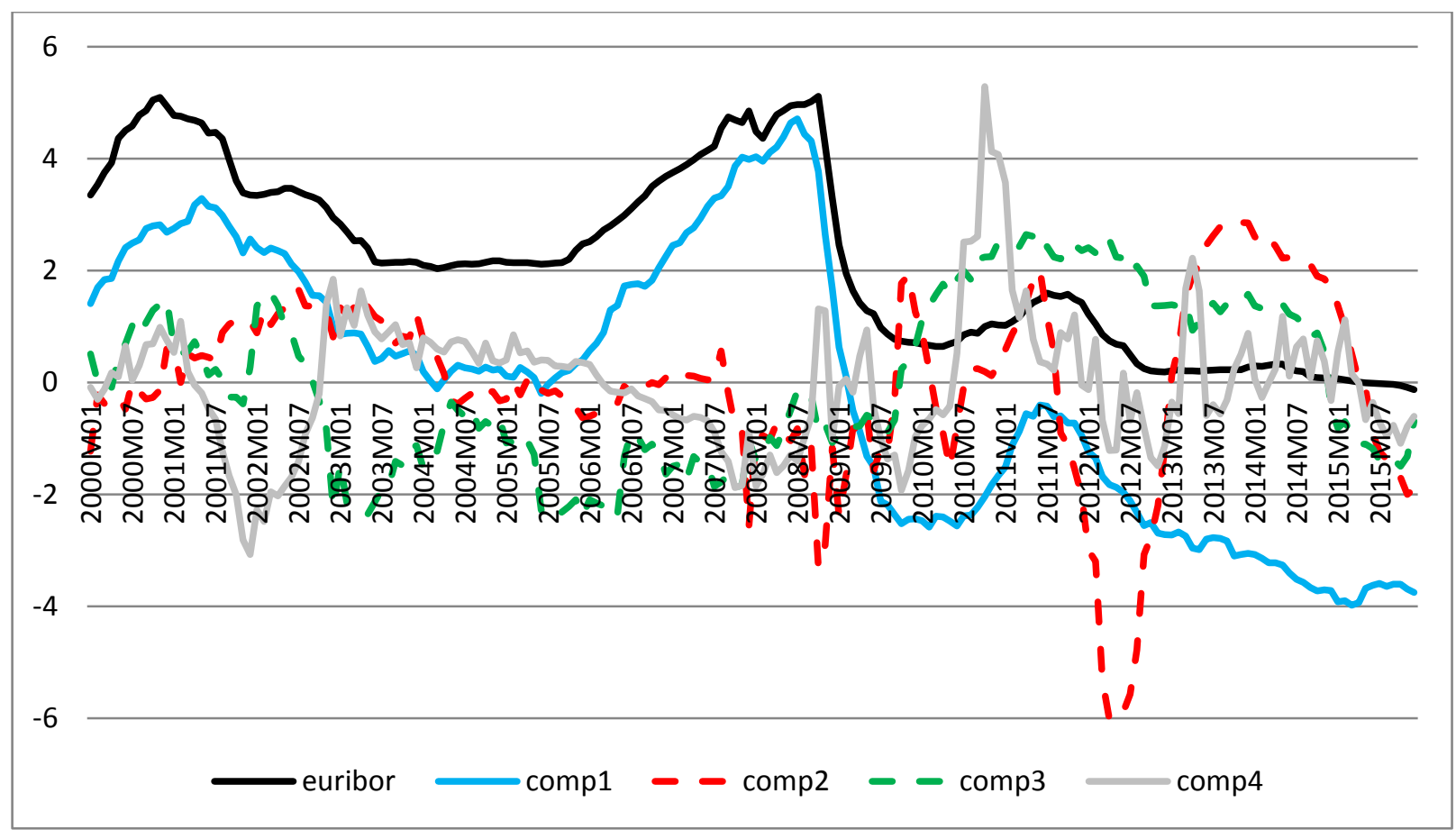

Source: authors' calculations on Eurostat and ECB SDW data. Comp1-4 are the principal components.

Figure 1b: 3 factor components of the index in Kucharčuková et al. (2016)

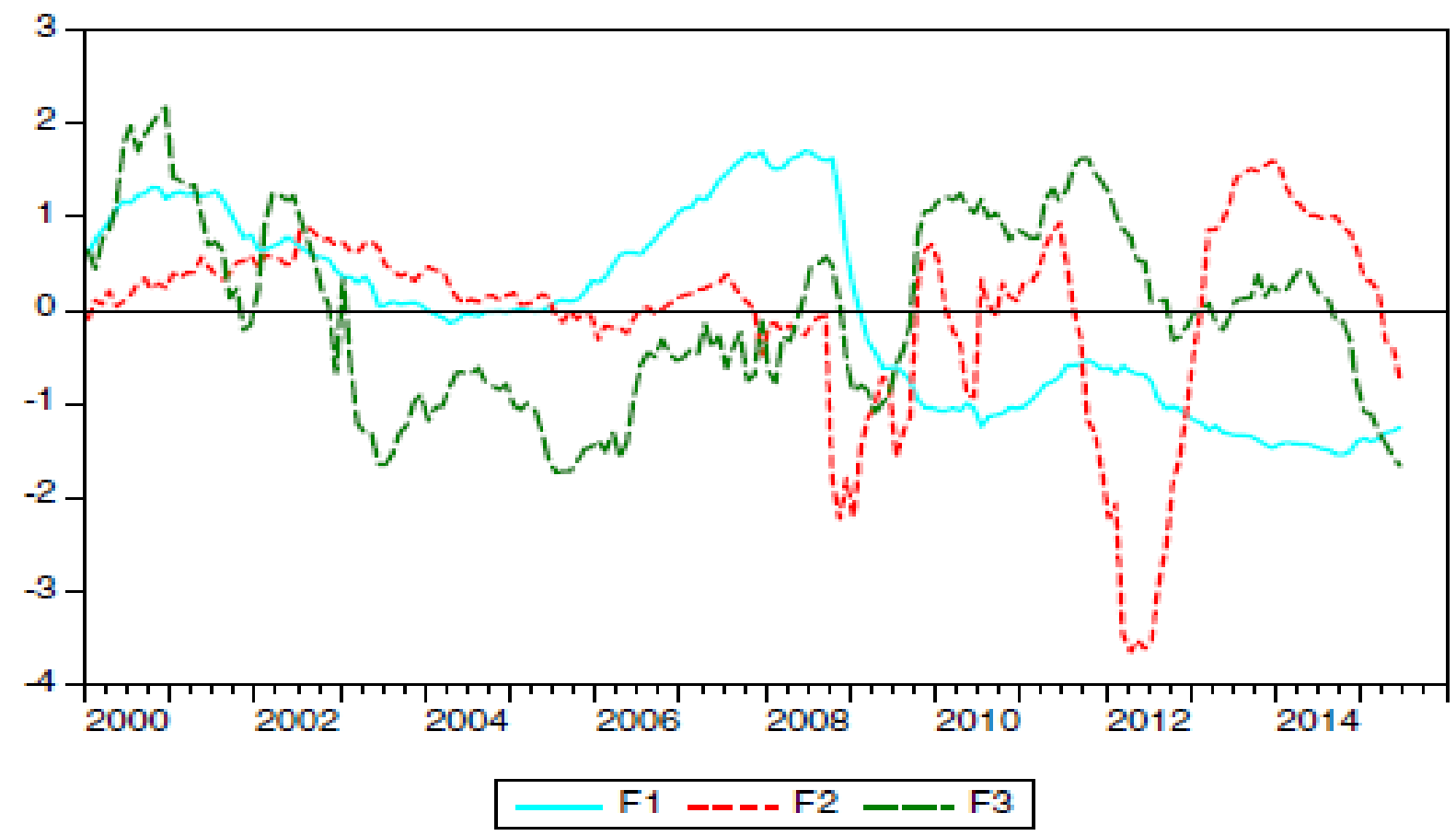

Source: Kucharčuková et al. (2016), F1-3 are the factor components. 
Figure 1c: comparison of indices for the euro area: our index vs. Wu and Xia (2016)

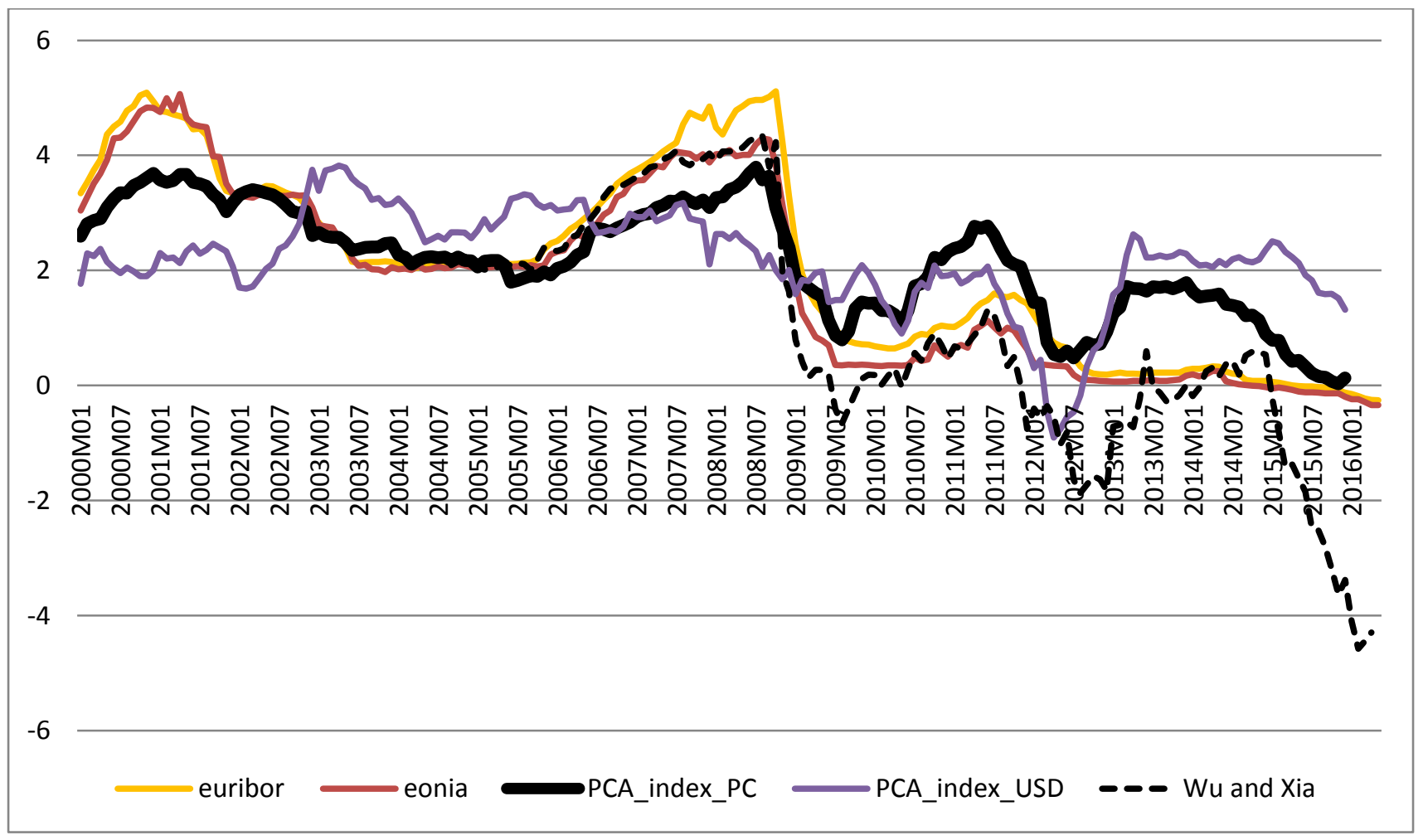

Source: authors' calculations on data from Eurostat and ECB SDW and data from Wu and Xia (2016). PCA_index_USD is the index computed without macroeconomic variables and with EUR/USD instead of NEER. The components are as in Figure 1a. 
Figure 1d: index computed with non-iterated factors vs. Euribor 3 months

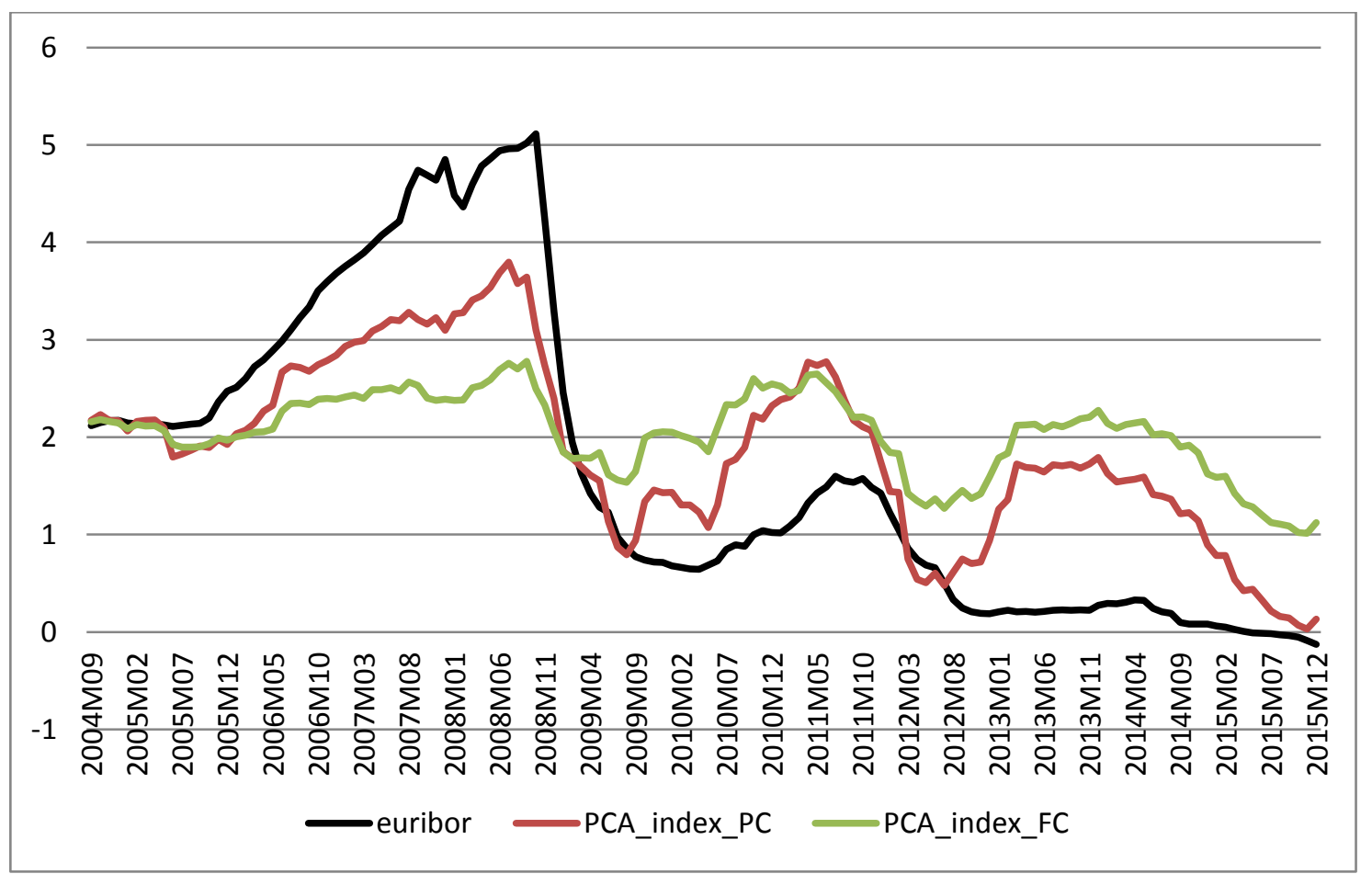

Source: authors' calculations on data from Eurostat and ECB SDW. PCA_index_FC is the index computed by using noniterated factors instead of components. 
Table 1: factor loadings for our index

\begin{tabular}{lllll} 
& F1 & F2 & F3 & F4 \\
\cline { 2 - 4 } RATES & & & & \\
EURIBOR3M & 0.97 & & & \\
EURIBOR12M & 0.96 & & & \\
EONIA & 0.95 & & & \\
BB_10Y & 0.74 & & &
\end{tabular}

$\begin{array}{ll}\text { MONETARY } & \\ \text { M1 } & 0.76 \\ \text { M2 } & 0.55 \\ \text { M2 } & 0.47\end{array}$

\begin{tabular}{lrrrr} 
BALANCE SHEET & & & & \\
TA & & 0.91 & & \\
LTRO & & 0.83 & & \\
CIC & & 0.06 & 0.59 & 0.56 \\
LIAB & & 0.91 & & \\
MRO & & -0.33 & & 0.85 \\
& & & & \\
MACRO\&FX & & & & \\
NEER_42 & 0.25 & -0.41 & 0.23 & -0.25 \\
HICP & 0.69 & 0.12 & -0.39 & 0.19 \\
UNEMP_RATE & -0.94 & 0.05 & -0.15 & -0.05 \\
& & & & \\
\hline \hline
\end{tabular}

Source: authors' calculations on data from Eurostat and ECB SDW. The details about variables and sources are in the Appendix. 
Figure 2: Computed shadow rates for the euro area

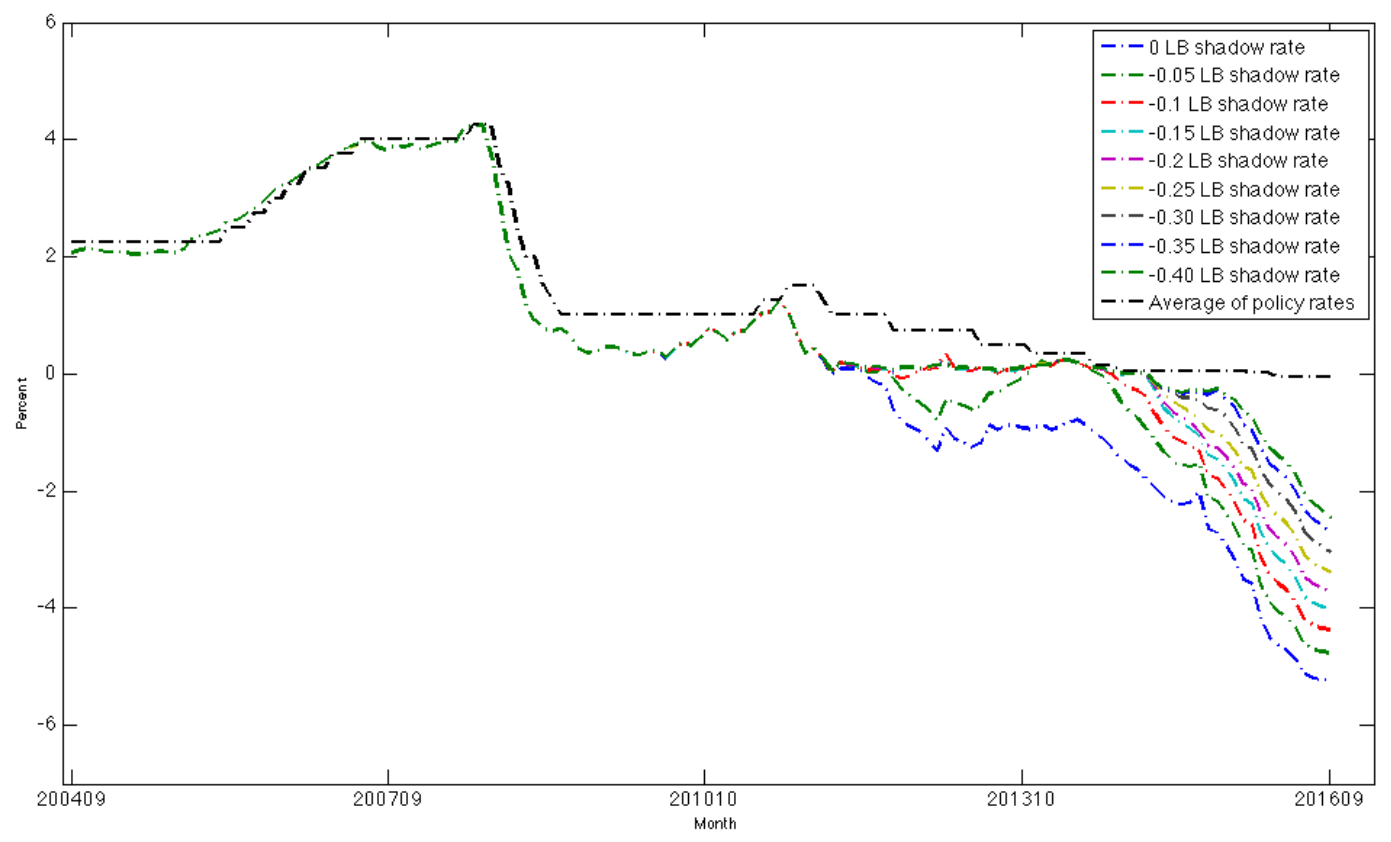

Source: authors' calculations on ECB data (with different minimum rates).

Figure 3: Euro area spread á la Baumeister and Benati (2010, 2013) compared to Euribor 3 months

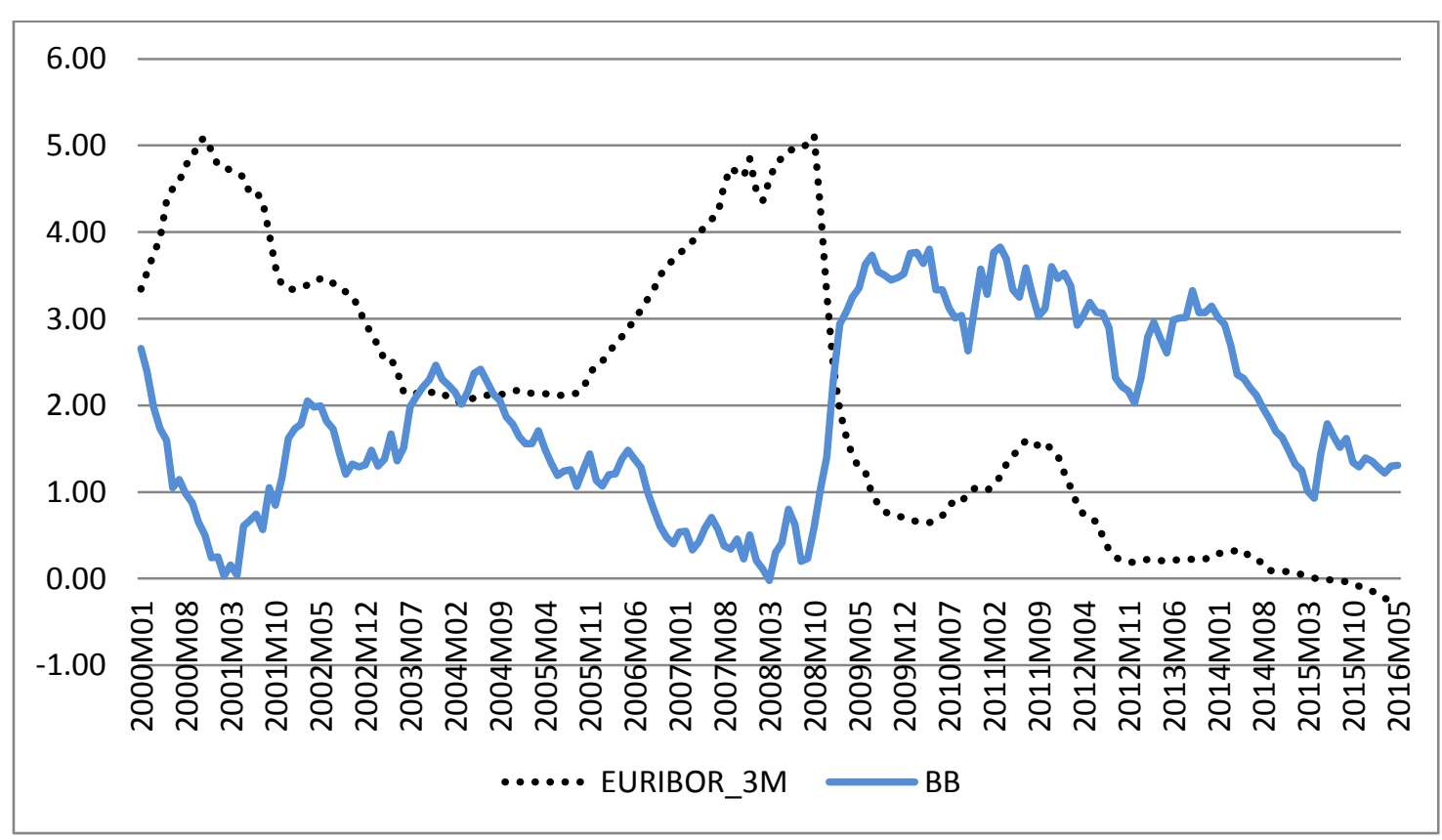

Source: authors' calculations on ECB SDW data. BB is the spread á la Baumeister and Benati (2010, 2013), defined as the difference between 10-years government benchmark bond yield and EONIA. 
Figure 4: Kucharčuková et al. (2016) MCI (Monetary Condition Index) compared to Euribor 3 months

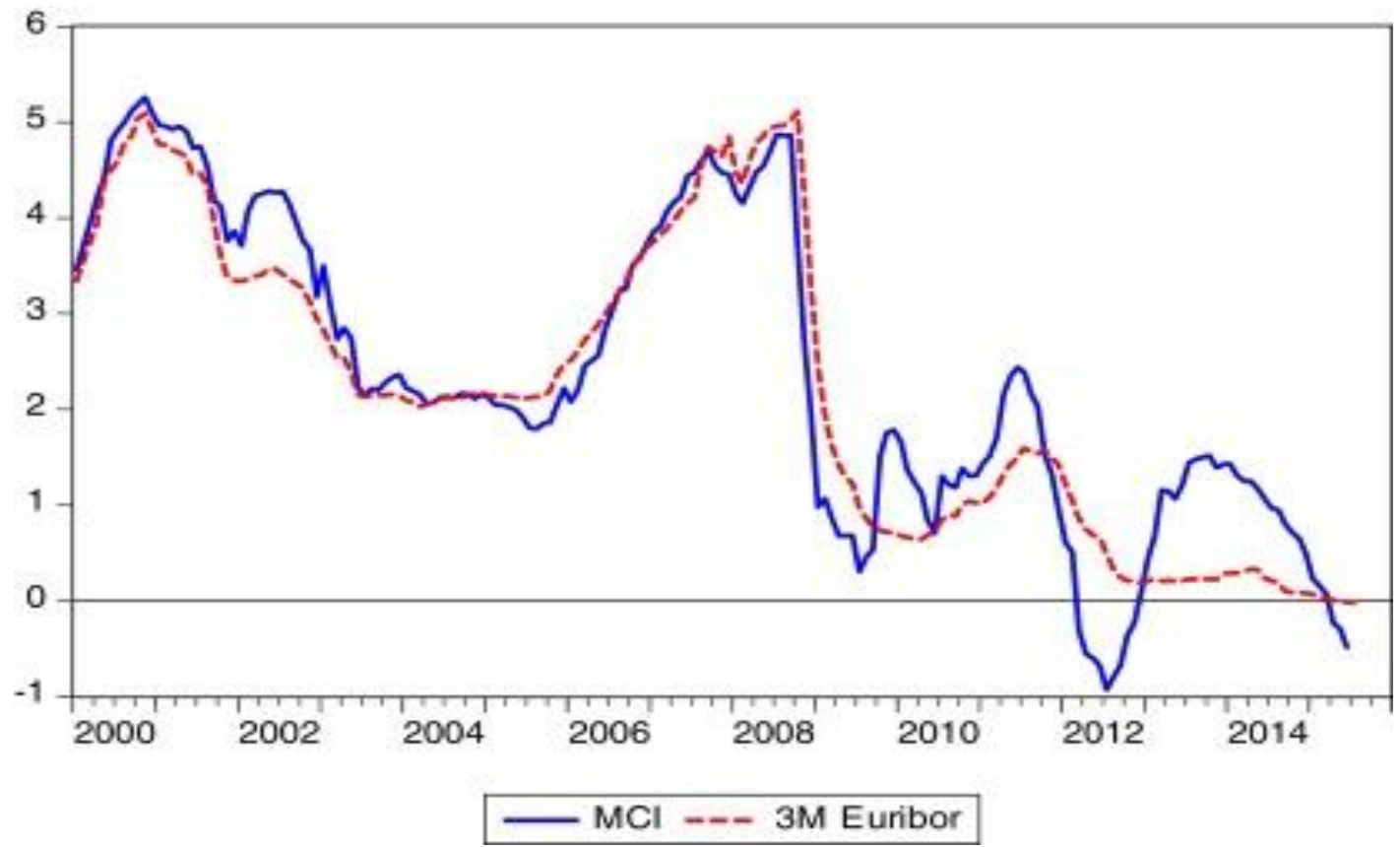

Source: Kucharčuková et al. (2016)

Figure 5: different measures of shadow rates for the U.S.

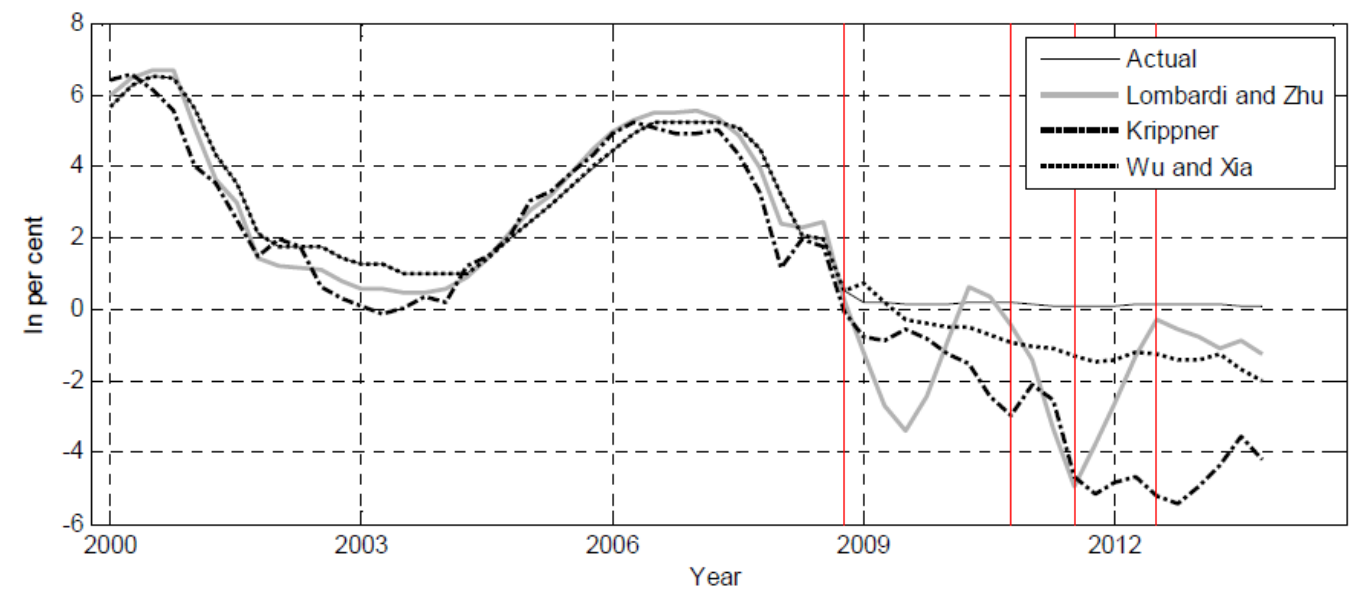

${ }^{1}$ The red vertical lines correspond to the dates of introduction of the major asset purchase programmes implemented by the Federal Reserve: LSAP1 (November 2008), LSAP2 (November 2010), MEP (September 2011) and LSAP3 (September 2012).

Sources: Federal Reserve, Krippner (2013a), Wu and Xia (2014), authors' calculations.

Source: Lombardi and Zhu (2014) 
Figure 6: Kortela (2016) shadow rates for the euro area and comparisons

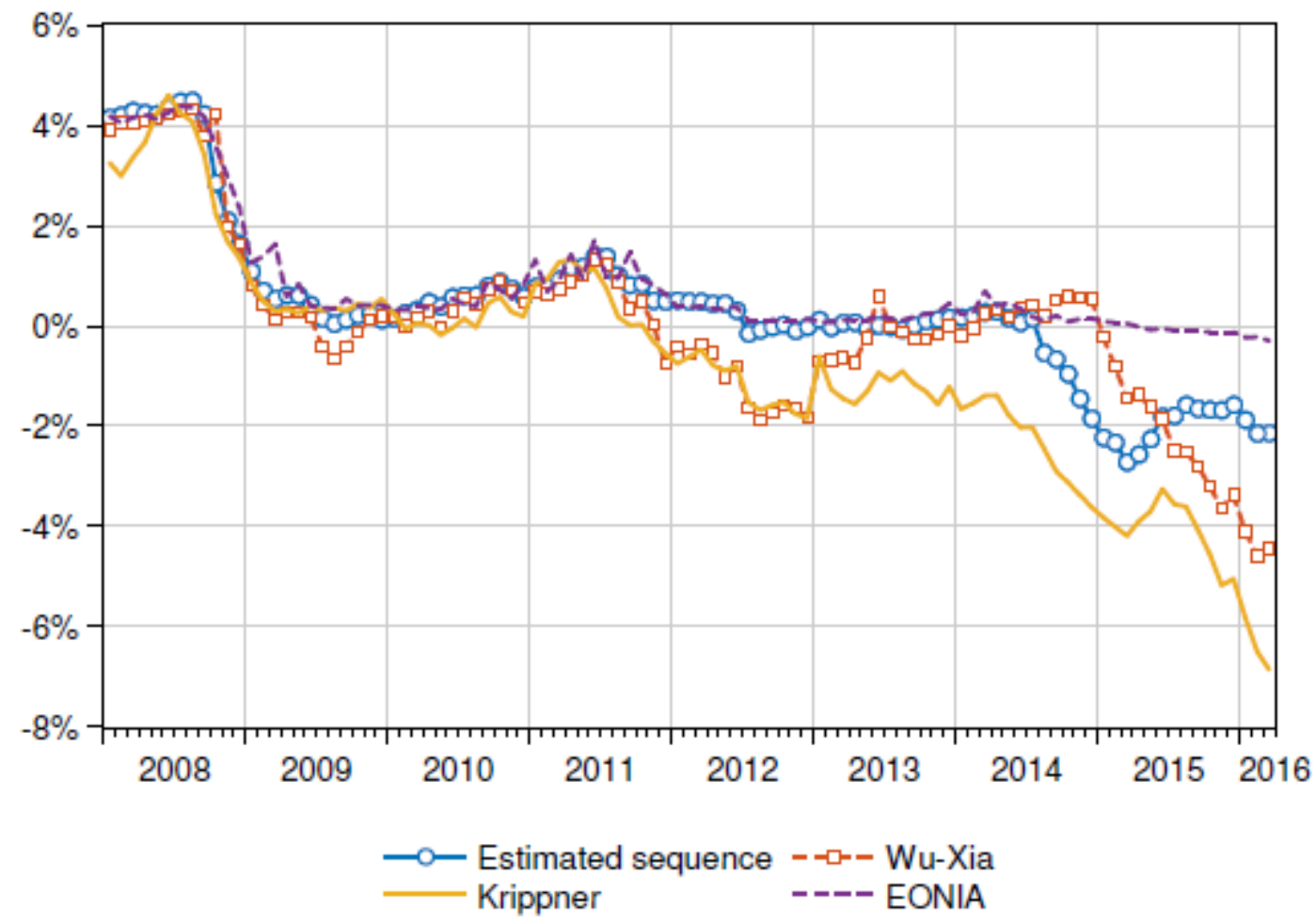

Source: Kortela (2016)

Figure 7a: Wu and Xia (2016) shadow rate for the euro area compared with main interest rates

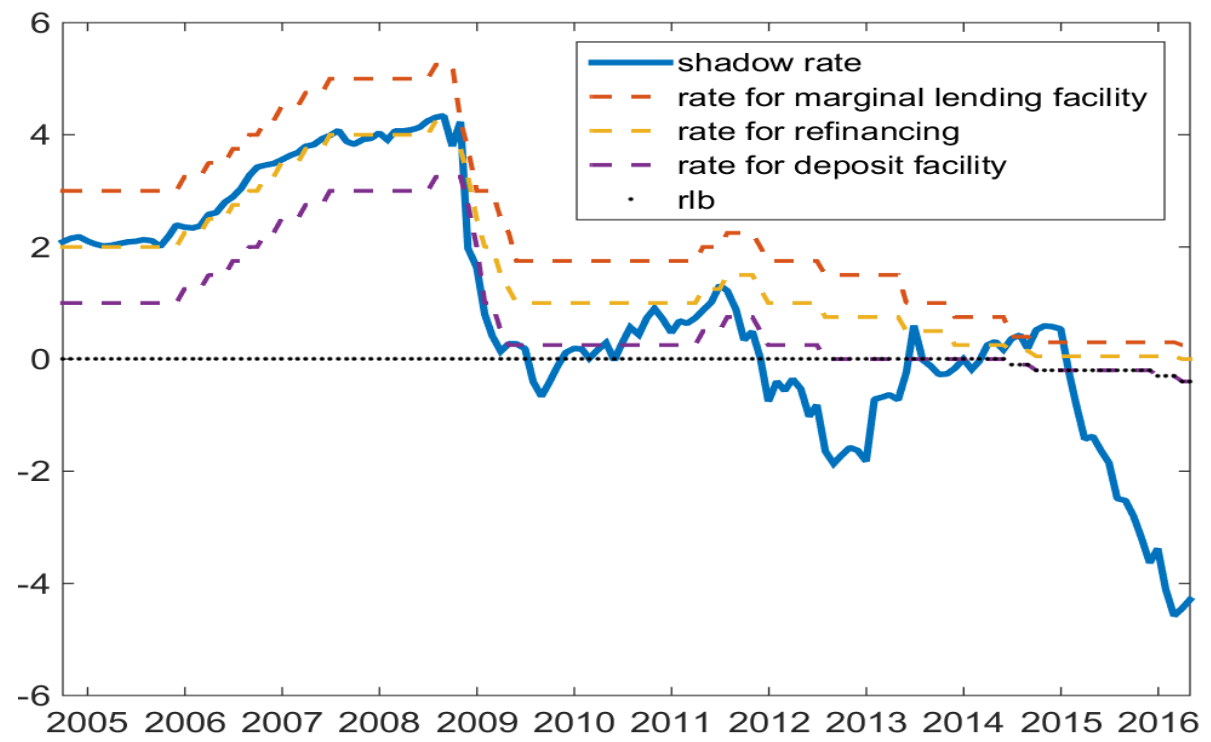

Source: http://faculty.chicagobooth.edu/jing.wu/research/data/WX.html based on Wu and Xia (2016). 
Figure 7b: Halberstadt and Krippner (2016) model-free Effective Monetary Stimulus (EMS) for the euro area

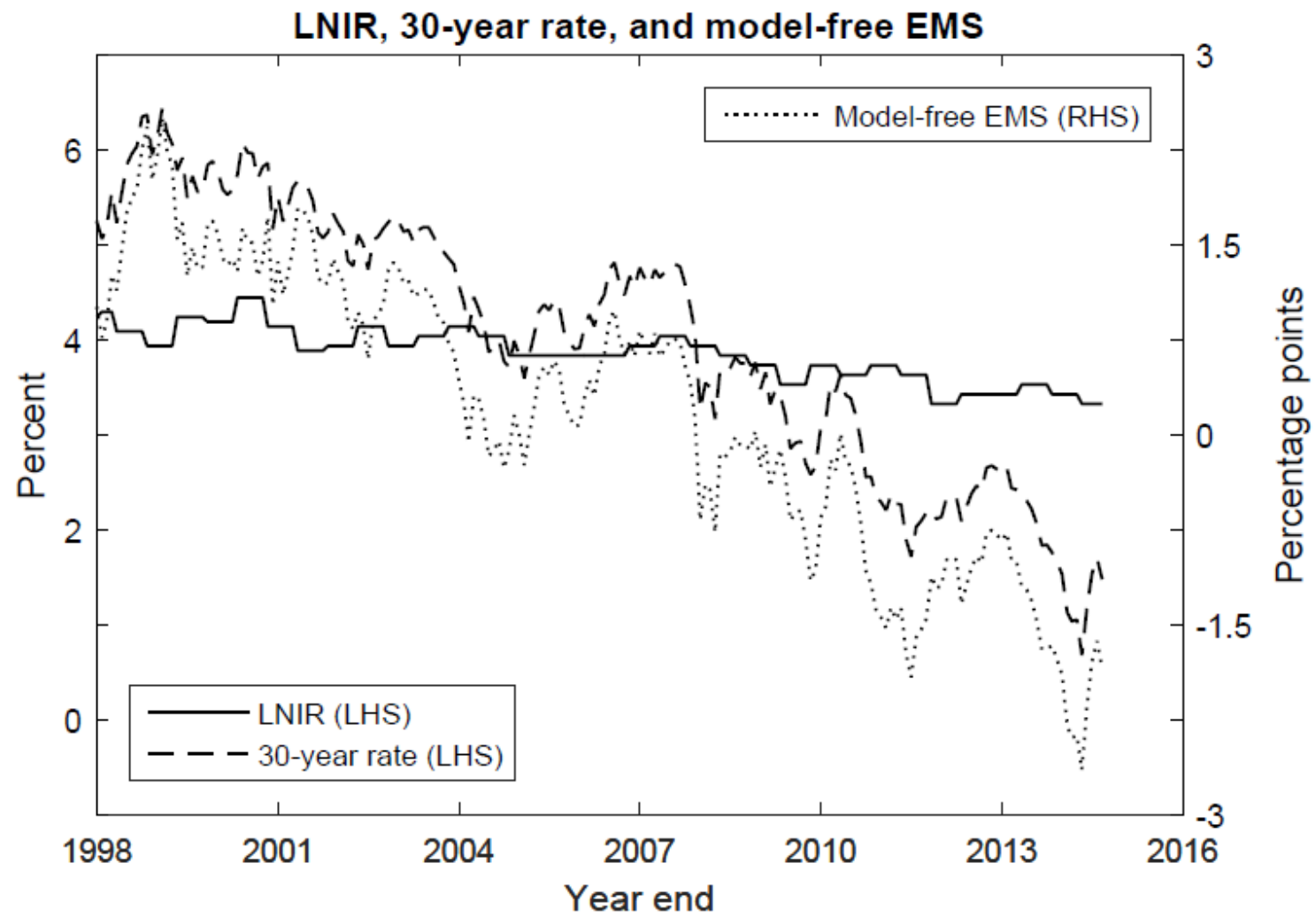

Source: Halberstadt and Krippner (2016), Fig.3.

Note: Here reported also the long-horizon nominal natural interest rate (LNIR) and 30-year rate. 
Table 2: summary of methods

\begin{tabular}{|c|c|c|c|c|c|}
\hline Paper & Method & Country & Data & + PROS & - CONS \\
\hline $\begin{array}{l}\text { Baumeister and } \\
\text { Benati }(2010,2013)\end{array}$ & $\begin{array}{l}\text { Spread between long and short- } \\
\text { term interest rates }\end{array}$ & $\begin{array}{l}\text { euro area, } \\
\text { Japan, U.S. } \\
\text { and U.K. }\end{array}$ & $\begin{array}{l}\text { 1970Q1-2008Q4 (euro } \\
\text { area) }\end{array}$ & $\begin{array}{l}\text { It's easy to compute } \\
\text { and to apply }\end{array}$ & $\begin{array}{l}\text { Does not take into } \\
\text { account other factors } \\
\text { which may have } \\
\text { influenced the spreads. }\end{array}$ \\
\hline $\begin{array}{l}\text { Kucharčuková et al. } \\
\text { (2016) }\end{array}$ & $\begin{array}{l}\text { Principal factors synthetic } \\
\text { index: } 14 \text { variables reflecting the } \\
\text { monetary conditions for the euro } \\
\text { area and these are divided in } 4 \\
\text { categories: interest rates and } \\
\text { spreads, monetary aggregates, } \\
\text { selected ECB balance sheet items } \\
\text { and, additionally, the exchange } \\
\text { rate vis-à-vis the USD. }\end{array}$ & Euro area & 2000M01-2015M07 & $\begin{array}{l}\text { More comprehensive } \\
\text { and relatively easy to } \\
\text { build }\end{array}$ & $\begin{array}{l}\text { Term structure model } \\
\text { not included, difficult } \\
\text { to compare to normal } \\
\text { rates (it's an index). } \\
\text { They do not include } \\
\text { any macroeconomic } \\
\text { variable. }\end{array}$ \\
\hline
\end{tabular}




\begin{tabular}{|c|c|c|c|c|c|}
\hline $\begin{array}{l}\text { Bluwstein and } \\
\text { Canova (2016) }\end{array}$ & $\begin{array}{l}\text { Principal component synthetic } \\
\text { index: U.S. and U.K. } \\
\text { (conventional and } \\
\text { unconventional) policy measures, } \\
\text { global real economy indicators, } \\
\text { oil prices, Eastern European and } \\
\text { EU (excluding the euro area) } \\
\text { financial indicators, global trade } \\
\text { price, and global equity indicators. } \\
\text { Moreover, nominal interest rates } \\
\text { are also added to the model to } \\
\text { identify conventional monetary } \\
\text { policy shocks. }\end{array}$ & $\begin{array}{l}\text { Euro area } \\
\text { (effect on euro } \\
\text { area and } 9 \\
\text { non- euro area } \\
\text { European } \\
\text { countries } \\
\text { (Czech } \\
\text { Republic, } \\
\text { Hungary, } \\
\text { Poland, } \\
\text { Romania, } \\
\text { Sweden, } \\
\text { Norway, } \\
\text { Denmark, } \\
\text { Bulgaria and } \\
\text { Switzerland)) }\end{array}$ & $\begin{array}{l}\text { from } 18 \text { December } 2008 \\
\text { until } 10 \text { May } 2014 \\
\text { (different frequencies) }\end{array}$ & $\begin{array}{l}\text { The effect coming } \\
\text { from monetary policy } \\
\text { measures of the U.S. } \\
\text { (and U.K.) is } \\
\text { considered. Still } \\
\text { relatively easy to } \\
\text { build. }\end{array}$ & $\begin{array}{l}\text { The term structure } \\
\text { model not included, } \\
\text { difficult to compare to } \\
\text { normal rates (it's an } \\
\text { index) }\end{array}$ \\
\hline $\begin{array}{l}\text { Lombardi and Zhu } \\
\text { (2014) }\end{array}$ & $\begin{array}{l}\text { Shadow rates based on: interest } \\
\text { rates, monetary aggregates and } \\
\text { Federal Reserve balance sheet } \\
\text { (assets and liabilities). They use } \\
\text { then a dynamic factor model with } \\
\text { missing observations to extract } \\
\text { common components from this } \\
\text { large set of variables. }\end{array}$ & U.S. & 1970M01-2013M12 & $\begin{array}{l}\text { Their approach looks } \\
\text { very much like a more } \\
\text { refined version of a } \\
\text { synthetic index. More } \\
\text { easy to compare with } \\
\text { normal rates. }\end{array}$ & $\begin{array}{l}\text { These are not an actual } \\
\text { interest rate faced by } \\
\text { economic agents and } \\
\text { may vary with the } \\
\text { practical choices } \\
\text { underlying their } \\
\text { calculations and } \\
\text { especially they depend } \\
\text { on: the specification of } \\
\text { the shadow/ZLB model } \\
\text { and the data and } \\
\text { method used for } \\
\text { estimation. They do } \\
\text { not include any } \\
\text { macroeconomic } \\
\text { variable. }\end{array}$ \\
\hline
\end{tabular}




\begin{tabular}{|c|c|c|c|c|c|}
\hline $\begin{array}{l}\text { Bauer and } \\
\text { Rudebusch (2015) }\end{array}$ & $\begin{array}{l}\text { Multifactor shadow rate term } \\
\text { structure model (SRTSM). } \\
\text { Shadow rates based on analytical } \\
\text { representation for bond prices in a } \\
\text { dynamic term structure models } \\
\text { (DTSMs) both Gaussian and } \\
\text { shadow. Macro-finance term } \\
\text { structure model also provided } \\
\text { (with CPI growth y-o-y and } \\
\text { unemployment gap). Minimum } \\
\text { rate set as zero. Their main aim } \\
\text { here is to check for the expected } \\
\text { duration of the ZLB period, which } \\
\text { can provide a useful measure of } \\
\text { the stance of monetary policy and } \\
\text { the tightness of the ZLB. }\end{array}$ & U.S. & $\begin{array}{l}\text { Estimated shadow rates } \\
\text { from } 2005 \text { to } 2014 \text {. Based } \\
\text { on monthly data } 1985 \mathrm{M} 1- \\
2014 \mathrm{M} 12 \text {. }\end{array}$ & $\begin{array}{l}\text { More easy to compare } \\
\text { with normal rates. } \\
\text { Includes also macro- } \\
\text { financial aspects. }\end{array}$ & $\begin{array}{l}\text { Not free of possible } \\
\text { numerical error } \\
\text { associated with } \\
\text { simulation methods. } \\
\text { Assumption of } \\
\text { stationarity across pre- } \\
\text { ZLB and ZLB periods }\end{array}$ \\
\hline $\begin{array}{l}\text { Lemke and Vladu } \\
\text { (2015) }\end{array}$ & $\begin{array}{l}\text { Shadow rates. Multifactor } \\
\text { shadow rate term structure model } \\
\text { (SRTSM) with estimated lower } \\
\text { bound ( } 10 \mathrm{bps}) \text { and not set to zero. }\end{array}$ & Euro area & 1999M01-2014M04. & $\begin{array}{l}\text { It performs well with } \\
\text { respect to the euro area } \\
\text { yield curve data. The } \\
\text { ECB interest rate cut } \\
\text { in June } 2014 \text { pushed } \\
\text { the authors to also } \\
\text { check for effects of } \\
\text { changes in this } \\
\text { "effective lower } \\
\text { bound" on the yield } \\
\text { curve by using the } \\
\text { forward curve } \\
\text { approximation by Wu } \\
\text { and Xia (2016). }\end{array}$ & $\begin{array}{l}\text { Generally, more } \\
\text { complicated to } \\
\text { reproduce (SRTSM). } \\
\text { They do not include } \\
\text { any macroeconomic } \\
\text { variable, which can } \\
\text { drive the rates. }\end{array}$ \\
\hline
\end{tabular}




\begin{tabular}{|c|c|c|c|c|c|}
\hline Kortela (2016) & $\begin{array}{l}\text { Shadow rates. Multifactor } \\
\text { shadow rate term structure model } \\
\text { (SRTSM) with time varying lower } \\
\text { bound. }\end{array}$ & Euro area & 1999M01-2016M03. & $\begin{array}{l}\text { A time-varying lower } \\
\text { bound might be } \\
\text { appropriate for the } \\
\text { euro area and such a } \\
\text { model outperforms the } \\
\text { constant lower bound } \\
\text { model in euro area } \\
\text { data. This may be also } \\
\text { seen as a new channel } \\
\text { via which monetary } \\
\text { policy may affect the } \\
\text { yield curve in a } \\
\text { shadow rate model. }\end{array}$ & $\begin{array}{l}\text { Generally, more } \\
\text { complicated to } \\
\text { reproduce (SRTSM). } \\
\text { They do not include } \\
\text { any macroeconomic } \\
\text { variable. }\end{array}$ \\
\hline Wu and Xia (2016) & $\begin{array}{l}\text { Shadow rates based on analytical } \\
\text { representation for bond prices in a } \\
\text { multifactor shadow rate term } \\
\text { structure model (SRTSM). } \\
\text { Minimum rate set as } 25 \text { basis } \\
\text { points. }\end{array}$ & $\begin{array}{l}\text { U.S., U.K. and } \\
\text { E.A. }\end{array}$ & $\begin{array}{l}\text { 1960M01-2015M11 (U.S.); } \\
\text { 2004M09-2016M04 (euro } \\
\text { area); 1990M01-2016M04 } \\
\text { (U.K.) }\end{array}$ & $\begin{array}{l}\text { More easy to compare } \\
\text { with normal rates. It } \\
\text { can be applied directly } \\
\text { to discrete-time data } \\
\text { and it is not based on } \\
\text { simulated methods. } \\
\text { Approximation is free } \\
\text { of any numerical error } \\
\text { associated with } \\
\text { simulation methods } \\
\text { and } \\
\text { numerical integration. }\end{array}$ & $\begin{array}{l}\text { These are not an actual } \\
\text { interest rate faced by } \\
\text { economic agents and } \\
\text { may vary with the } \\
\text { practical choices } \\
\text { underlying their } \\
\text { calculations and } \\
\text { especially they depend } \\
\text { on: the specification of } \\
\text { the shadow/ZLB model } \\
\text { and the data and } \\
\text { method used for } \\
\text { estimation. Generally, } \\
\text { more complicated to } \\
\text { reproduce (SRTSM). } \\
\text { They do not include } \\
\text { any macroeconomic } \\
\text { variable. }\end{array}$ \\
\hline
\end{tabular}




\begin{tabular}{|c|c|c|c|c|c|}
\hline $\begin{array}{l}\text { Krippner (2014, } \\
\text { 2016) }\end{array}$ & $\begin{array}{l}\text { Model-based Economic stimulus } \\
\text { measure (EMS). It aggregates } \\
\text { expected short rates relative to } \\
\text { their long-run expectation from } \\
\text { the same estimated model (from a } \\
\text { shadow/ZLB Gaussian affine term } \\
\text { structure model (G-ATSM)). It } \\
\text { approximates forward rates in a } \\
\text { shadow-rate context as the sum } \\
\text { of shadow forward rates and an } \\
\text { option effect, both of which are } \\
\text { available analytically. The EMS, } \\
\text { this measure is obtained by } \\
\text { calculating the total area between } \\
\text { the expected path of the short term } \\
\text { shadow rates truncated at zero and } \\
\text { the long-horizon nominal natural } \\
\text { interest rate (LNIR) proxy. }\end{array}$ & U.S. & $\begin{array}{l}\text { Estimated from } 2008 \mathrm{M} 12 \text {. } \\
\text { The sample period is } \\
\text { 1985M11 to the latest } \\
\text { available month-end data at } \\
\text { the time of estimation. }\end{array}$ & $\begin{array}{l}\text { More consistent and } \\
\text { comparable across } \\
\text { conventional and } \\
\text { unconventional } \\
\text { monetary policy } \\
\text { environments, and are } \\
\text { less subject to } \\
\text { variation with } \\
\text { modelling choices. it } \\
\text { allows the } \\
\text { decomposition of the } \\
\text { EMS into expected } \\
\text { policy and risk } \\
\text { premium components. }\end{array}$ & $\begin{array}{l}\text { Complicate to } \\
\text { reproduce and to give } \\
\text { them an economic } \\
\text { intuition. It is in } \\
\text { continuous-time. This } \\
\text { may be not easy to } \\
\text { apply in a discrete-time } \\
\text { setup. }\end{array}$ \\
\hline $\begin{array}{l}\text { Halberstadt and } \\
\text { Krippner (2016) }\end{array}$ & $\begin{array}{l}\text { Model-free Economic stimulus } \\
\text { measure (EMS): defined as the } \\
\text { area between the lower-bounded } \\
\text { nominal forward rate curve and } \\
\text { the long-horizon nominal natural } \\
\text { interest rate (LNIR, based on } \\
\text { Consensus Forecast), out to a } \\
\text { given horizon (in this case } 10 \\
\text { years). The measure is built by } \\
\text { using only observable data. } \\
\text { Model-based Economic stimulus } \\
\text { measure (EMS) also provided. }\end{array}$ & E.A. & $\begin{array}{l}\text { Data from 1993M4 to } \\
\text { 1998M12 as the training } \\
\text { sample for estimations. } \\
\text { The actual estimation } \\
\text { sample is 1999M01- } \\
\text { 2015M05. }\end{array}$ & $\begin{array}{l}\text { Model-free EMS: } \\
\text { more consistent and } \\
\text { comparable across } \\
\text { conventional and } \\
\text { unconventional } \\
\text { monetary policy } \\
\text { environments, and are } \\
\text { less subject to } \\
\text { variation with } \\
\text { modelling choices and } \\
\text { estimation methods, } \\
\text { being based on } \\
\text { observables only. }\end{array}$ & $\begin{array}{l}\text { Model-free EMS: it is } \\
\text { dependent on the proxy } \\
\text { used for the LNIR and } \\
\text { on CF surveys. It does } \\
\text { not allow the } \\
\text { decomposition of the } \\
\text { EMS into expected } \\
\text { policy and risk } \\
\text { premium components. }\end{array}$ \\
\hline
\end{tabular}


Table 3: Monetary policy measures and inflation

Paper

Effect on inflation
Baumeister and Benati (2010, 2013)

Chen et al. (2015)

Kucharčuková et al. (2016)

Bluwstein and Canova (2016)

Lombardi and Zhu (2014)

Wu and Xia (2016)

Halberstadt and Krippner (2016)
ECB (2017): positive contribution of UMP shocks to inflation. Among the two considered channels, the exchange rate channel is rather strong when moved by monetary policy shocks but even stronger when the exchange rate is moved by conventional monetary policy shocks.

QE measures which lower the U.S. corporate spread have had sizeable effects, which vary significantly across regions and individual economies.

The transmission of Unconventional Monetary Policy (UMP) to prices is quicker.

Following a UMP shock inflation significantly and persistently increases, while real activity responses are negative on impact and then insignificant. In case of conventional monetary policy shock, the inflation does not significantly react.

Monetary policy shocks estimated with short-term rates would severely understate the true extent of monetary expansion afforded by non-standard policy measures implemented after the breakout of the financial crisis.

Fed has used unconventional policy measures to successfully lower the shadow rate, and these measures have been more helpful to stimulate the economy (lowering unemployment rate) than a historical version of the Taylor rule.

Comunale and Kunovac (2017): the shadow rates are taken as the difference between the euro area and U.S. rates. The decisions coming from the U.S. on conventional and unconventional monetary policy matter for the inflation dynamics in the euro area.

The EMS measures are used to capture monetary policy stance. Their results indicate that the euro area monetary policy has helped to keep inflation and economic activity higher than they might have been otherwise. 
Figure 8: NRR for the U.S. (Laubach and Williams)

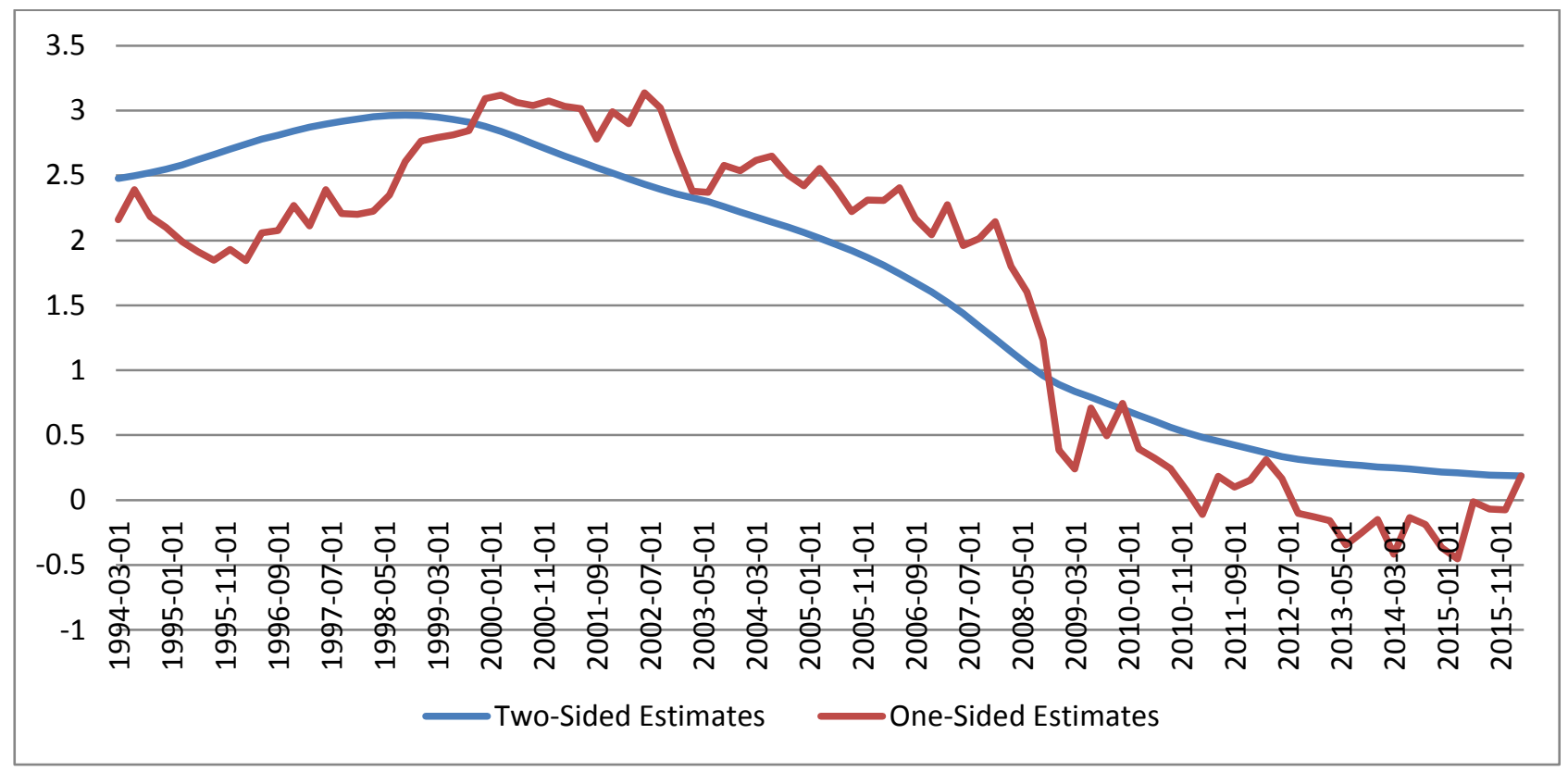

Source: authors' calculations on data from Laubach and Williams (2015).

Figure 9: Comparison Wu and Xia (2016) v. Laubach and Williams (2015) and short-term rates for the U.S.

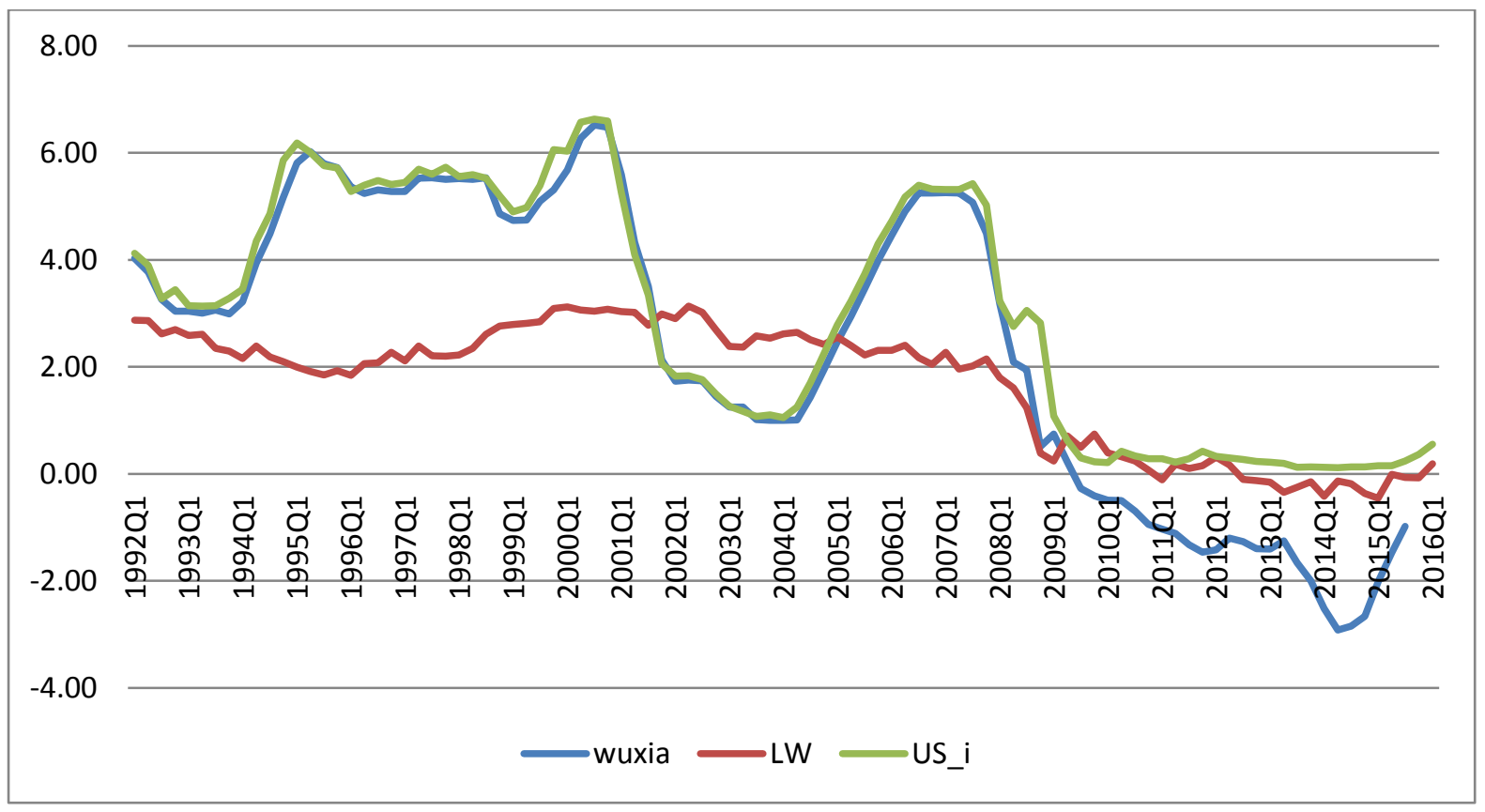

Source: authors' calculations on data from Wu and Xia (2016), Laubach and Williams (2015) and OECD. 
Figure 10: Comparison NRRs: Laubach and Williams (2003) v. Lubik and Matthes (2015)

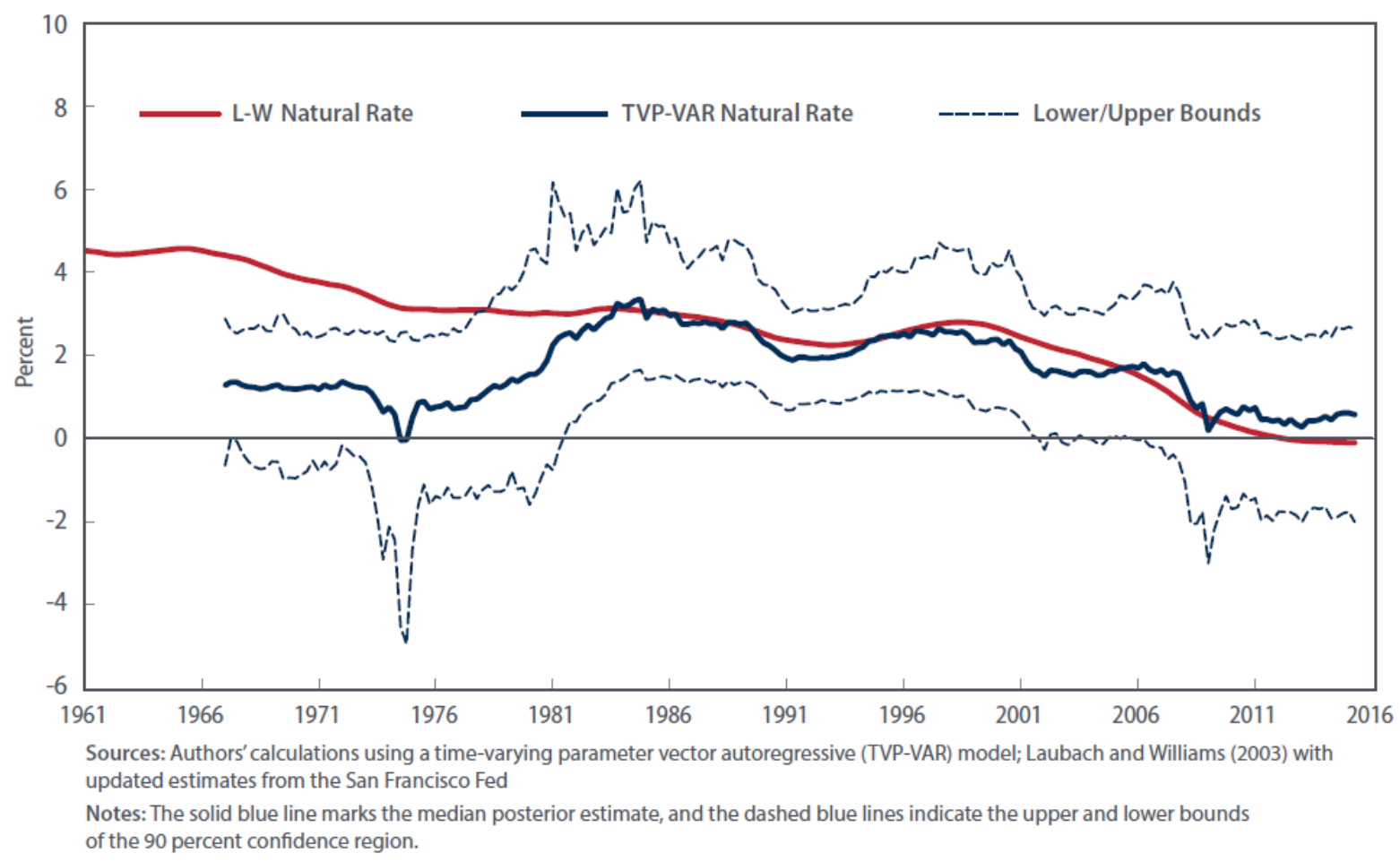

Source: Lubik and Matthes (2015) 
Figure 11: NRRs for the euro area (12 members) from Belke and Klose (2016): ex-ante twosided

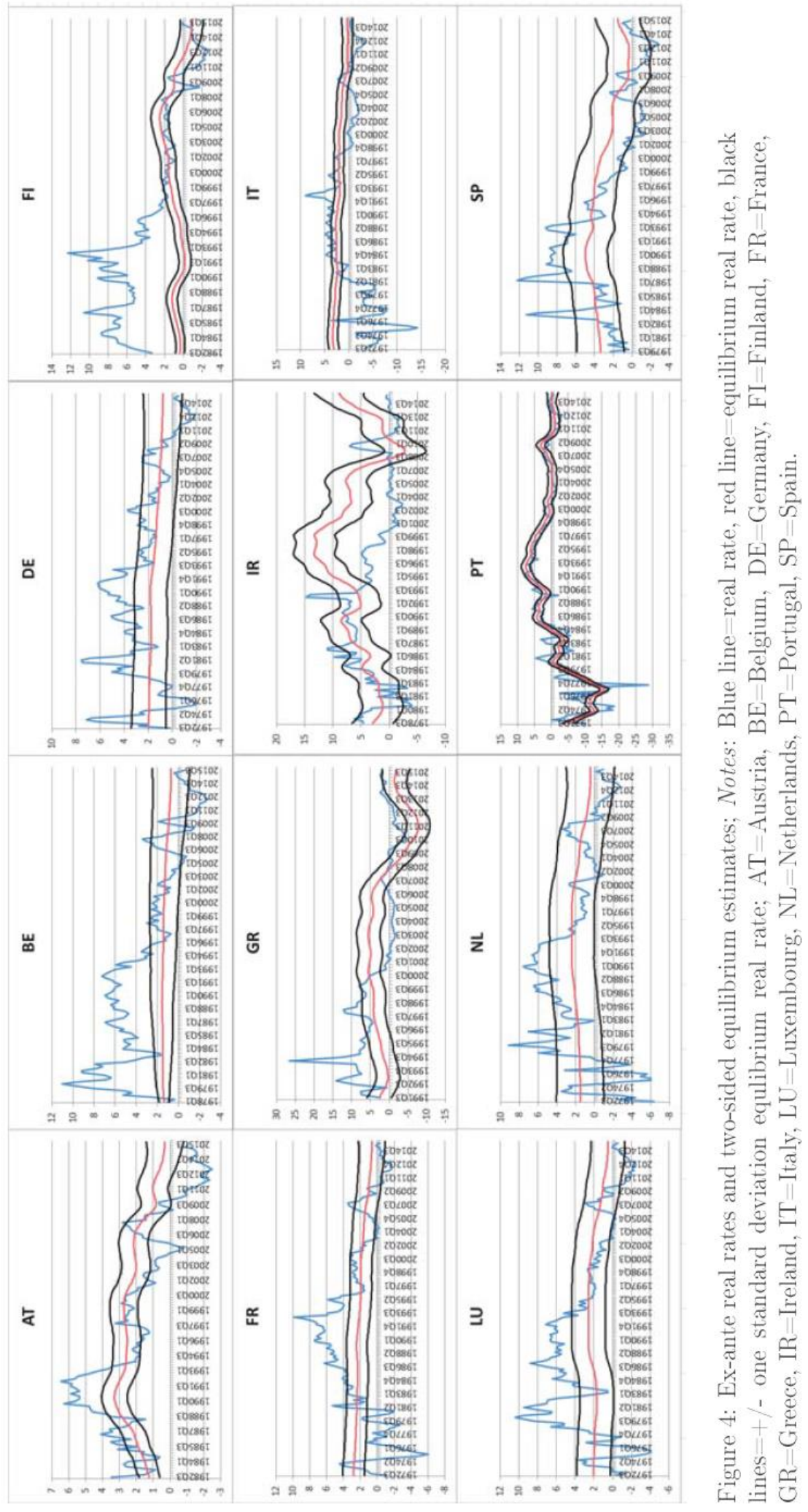

Source: Belke and Klose (2016) 
Figure 12a: NRR for the euro area ( $\left.\mathrm{r}^{*}\right)$ and gaps from Holston et al. (2016)
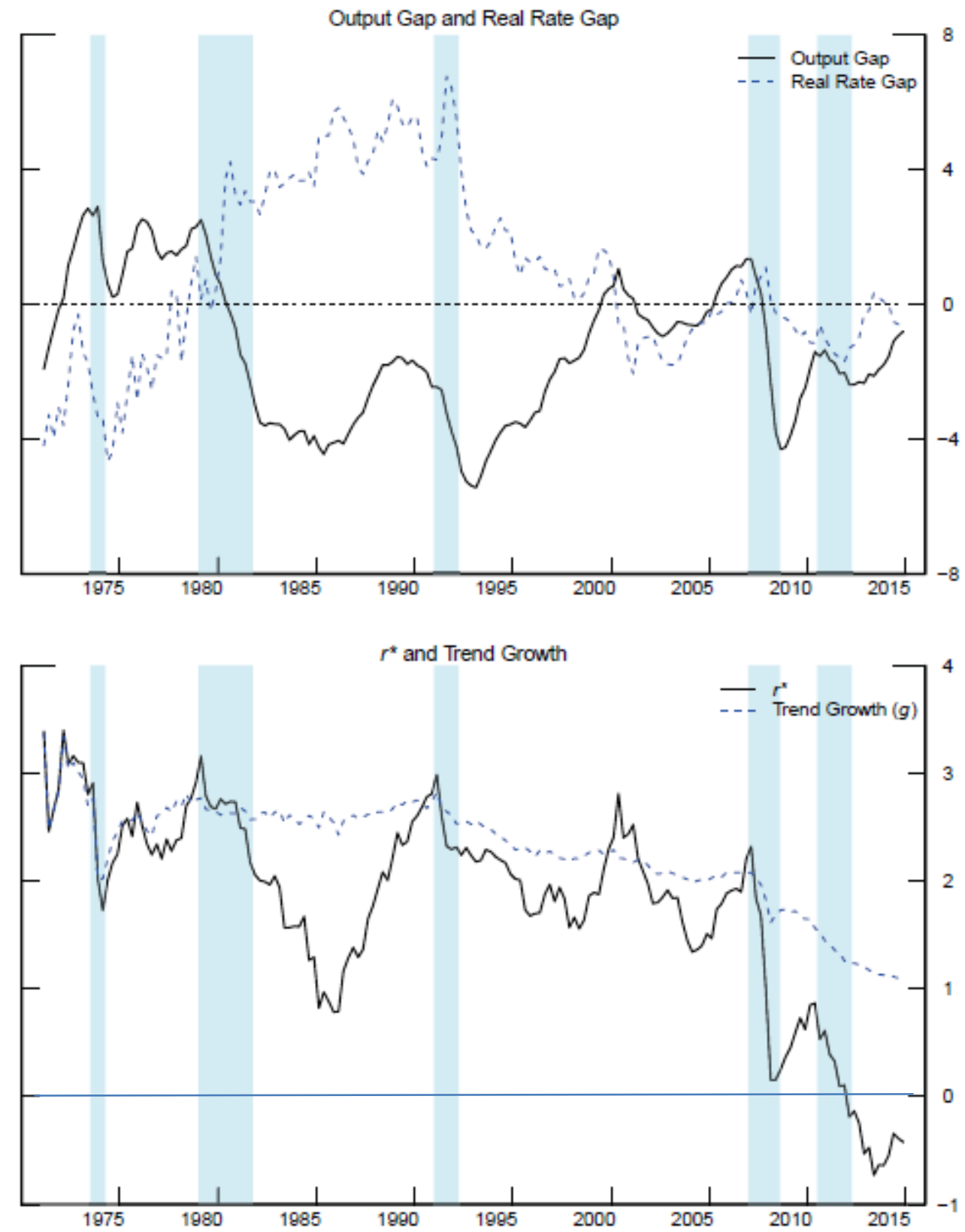

Source: Holston et al. (2016)

Note: the horizontal line in the second figure has been added by the authors of this paper. 
Figure 12b: NRR for the U.S. ( $\left.r^{*}\right)$ and gaps from Holston et al. (2016)
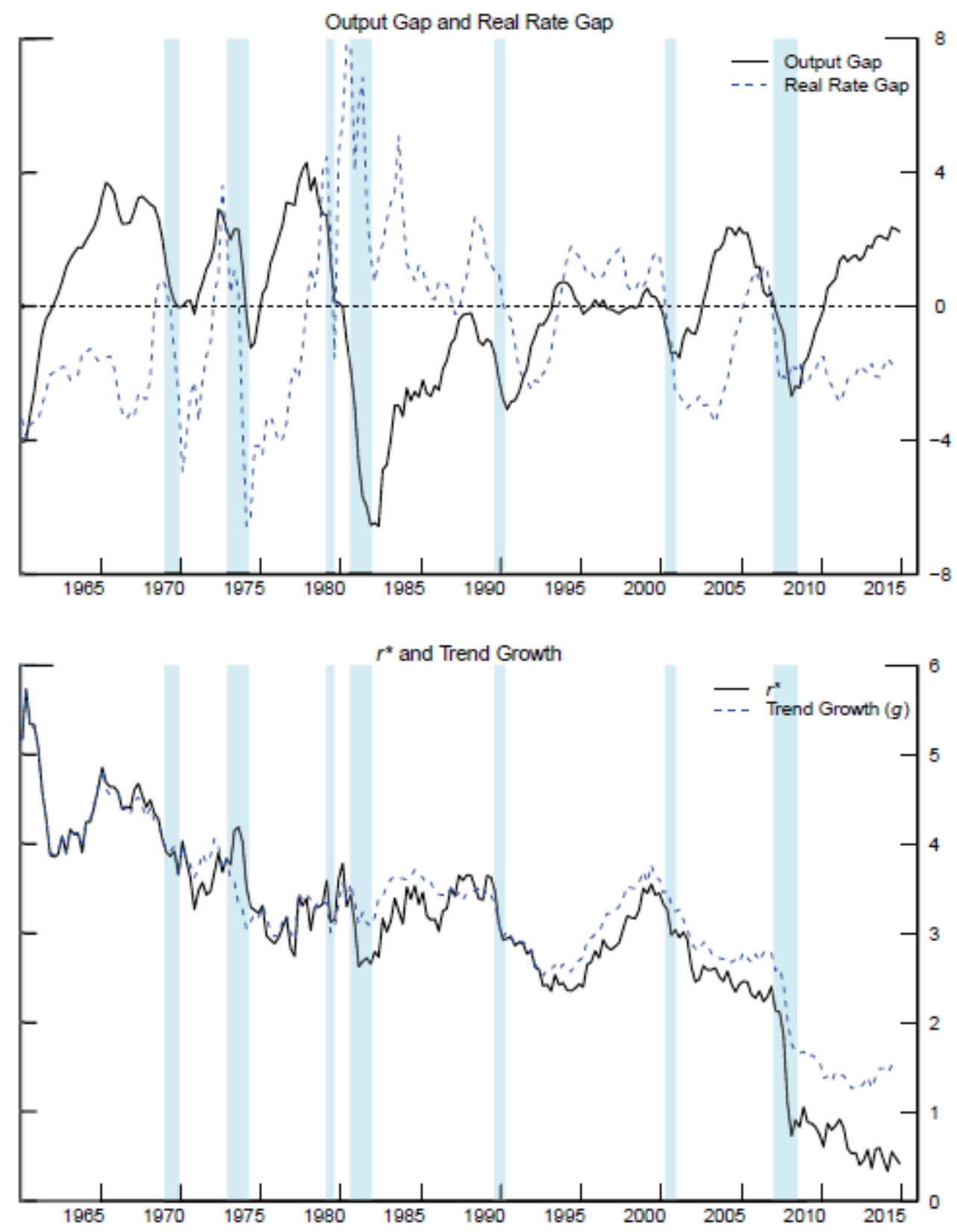

Source: Holston et al. (2016) 


\section{Figure 13: new estimates of NRR for the euro area}

FIGURE 9. Alternative estimates of the Euro area natural rate of interest.

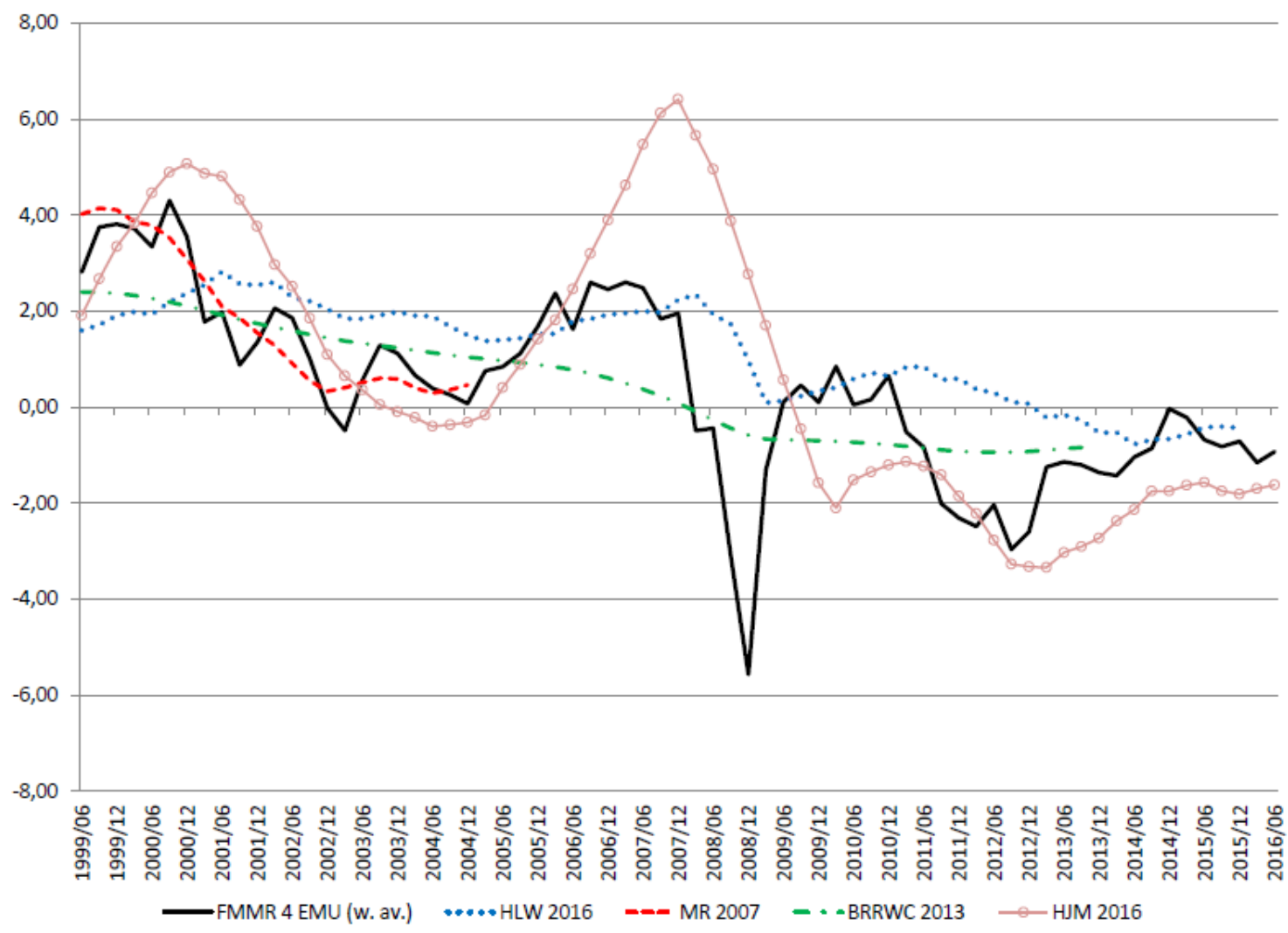

Note. FMMR 4EMU is the average of the national NRI estimated for the largest for countries in this paper, weighted by the share of each country in the nominal GDP of EMU4. HLW 2016 is the Euro area NRI estimated by Holston et al. (2016). MR 2007 is the baseline Euro area NRI as estimated in Mésonnier and Renne (ibid.). BRRWC 2013 refers to the baseline Euro area NRI estimated in Bouis et al. (2013). Last, HJM 2016 is the DSGE estimate of Haavio et al. (2016)

Source: Fries et al. (2016) 
Figure 14: "Finance-neutral" NRR for the U.S. (Juselius et al., 2016)

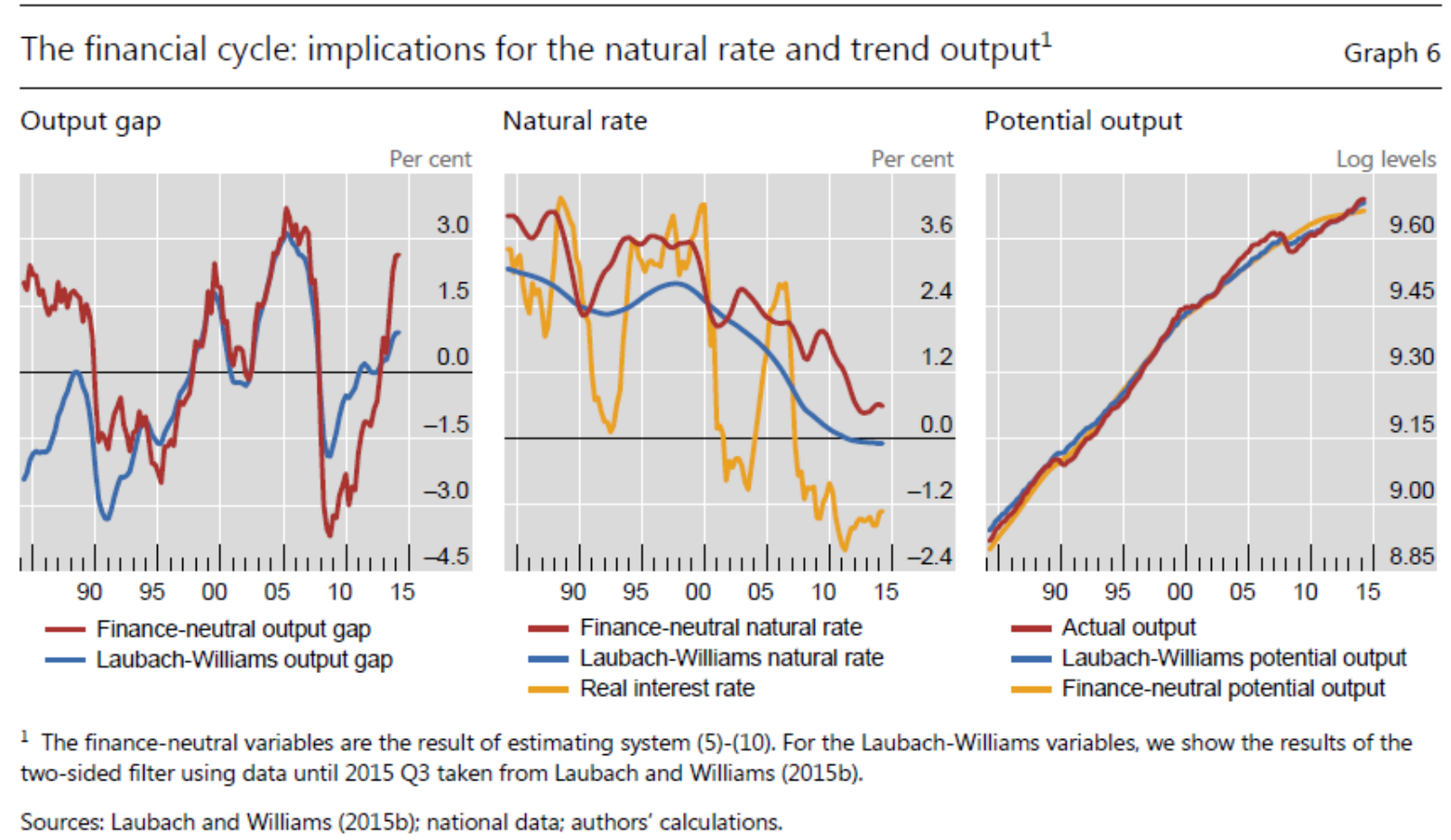

Source: Juselius et al. (2016)

Figure 15: NRR vs. Shadow NRR for the U.S. (Pescatori and Turunen, 2015)

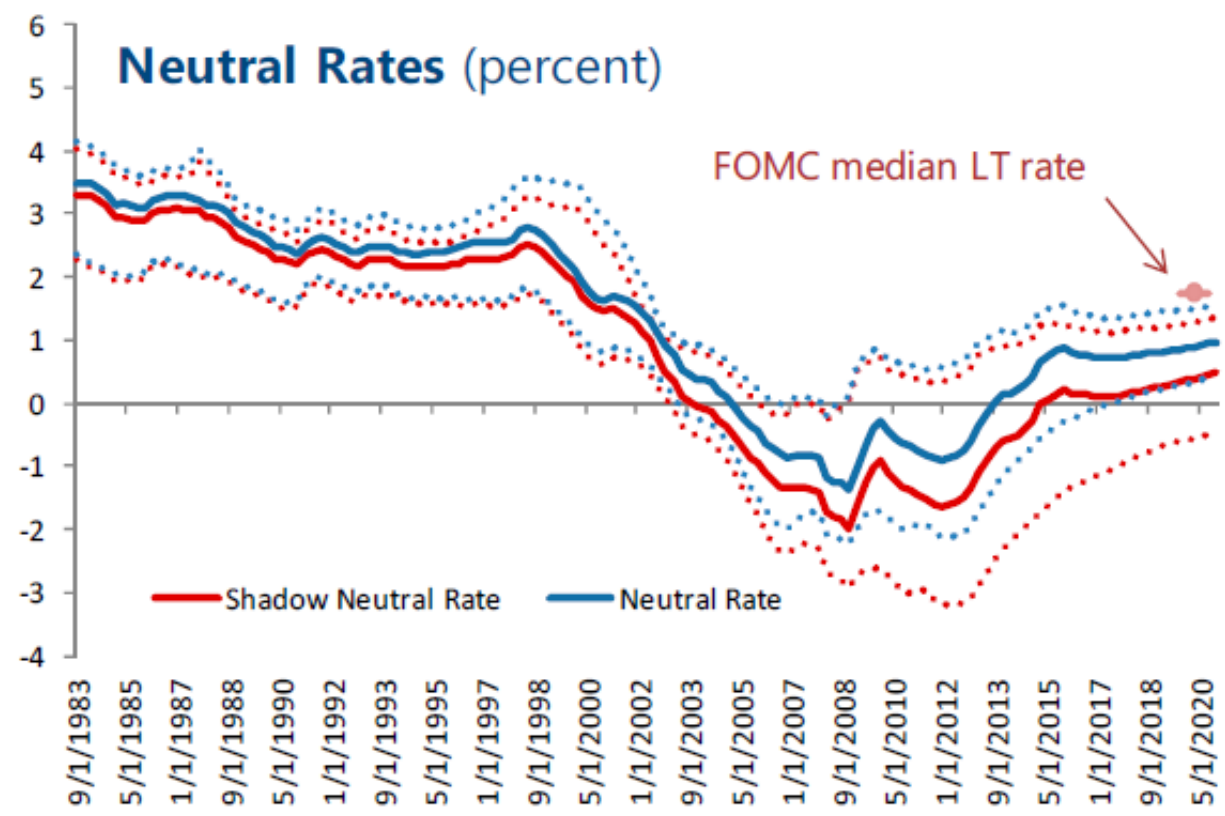

Source: Pescatori and Turunen (2015) 


\section{APPENDIX: Data description}

\section{A.1. Series used to compute the synthetic index}

\begin{tabular}{|c|c|c|c|c|c|c|c|}
\hline Variable & Description & Source & Obs & Mean & Std. Dev. & Min & Max \\
\hline euribor_3m & $\begin{array}{l}\text { Euro area (changing composition) - Euribor 3-month - Historical close, } \\
\text { average of observations through period - Euro, provided by Reuters }\end{array}$ & ECB SDW & 197 & 2.13 & 1.65 & -0.30 & 5.11 \\
\hline euribor_12m & $\begin{array}{l}\text { Euro area (changing composition) - Euribor 1-year - Historical close, } \\
\text { average of observations through period - Euro, provided by Reuters }\end{array}$ & ECB SDW & 197 & 2.39 & 1.57 & -0.01 & 5.39 \\
\hline eonia & $\begin{array}{l}\text { Euro area (changing composition) - Money Market - Eonia rate - } \\
\text { Historical close, average of observations through period - Euro, } \\
\text { provided by ECB }\end{array}$ & ECB SDW & 197 & 1.89 & 1.63 & -0.34 & 5.06 \\
\hline bb_10y & $\begin{array}{l}\text { Euro area (changing composition) } 10 \text {-year Government Benchmark } \\
\text { bond yield - Euro, provided by ECB }\end{array}$ & ECB SDW & 197 & 3.77 & 1.14 & 0.85 & 5.70 \\
\hline $\mathrm{m} 1$ & $\begin{array}{l}\text { Monetary aggregate M1, All currencies combined - Euro area } \\
\text { (changing composition) counterpart, Non-MFIs excluding central } \\
\text { government sector, denominated in Euro, data Working day and } \\
\text { seasonally adjusted, Millions of Euro }\end{array}$ & ECB SDW & 196 & 8.07 & 3.80 & 0.23 & 17.84 \\
\hline $\mathrm{m} 2$ & $\begin{array}{l}\text { Monetary aggregate M2, All currencies combined - Euro area } \\
\text { (changing composition) counterpart, Non-MFIs excluding central } \\
\text { government sector, denominated in Euro, data Working day and } \\
\text { seasonally adjusted, Millions of Euro }\end{array}$ & ECB SDW & 196 & 5.91 & 2.67 & 1.29 & 11.79 \\
\hline $\mathrm{m} 3$ & $\begin{array}{l}\text { Monetary aggregate } \mathrm{M} 3 \text {, All currencies combined - Euro area } \\
\text { (changing composition) counterpart, Non-MFIs excluding central } \\
\text { government sector, denominated in Euro, data Working day and }\end{array}$ & ECB SDW & 196 & 5.50 & 3.55 & -2.09 & 12.64 \\
\hline
\end{tabular}


Euro area (changing composition) - Total assets/liabilities, All currencies combined - World not allocated (geographically) counterpart, Millions of Euro

Longer-term refinancing operations, Euro - Euro area (changing composition) counterpart, Millions of Euro

Currency in circulation, All currencies combined - Euro area (changing composition) counterpart, Non-MFIs excluding central government sector, denominated in Euro, data Neither seasonally nor working day adjusted

Euro area (changing composition) - Liabilities to euro area credit institutions related to MPOs denominated in euro, Euro - Euro

Main refinancing operations, Euro - Euro area (changing composition) counterpart, Millions of Euro

Rate of change. Nominal Effective Exchange Rate vis-à-vis 42 partners Rate of change. Harmonised Index of Consumer Prices (All items) $(2015=100)$

Unemployment according to ILO definition - Total, Percentage of active population, Seasonally adjusted data, not calendar adjusted data

\begin{tabular}{|c|c|c|c|c|c|}
\hline ECB SDW & 198 & 9.81 & 16.90 & -24.50 & 60.80 \\
\hline ECB SDW & 198 & 27.05 & 60.95 & -55.00 & 244.90 \\
\hline ECB SDW & 196 & 7.78 & 9.76 & -31.19 & 42.32 \\
\hline ECB SDW & 198 & 24.79 & 63.13 & -56.90 & 283.70 \\
\hline ECB SDW & 198 & 6.21 & 49.40 & -84.90 & 271.60 \\
\hline Eurostat & 192 & 0.88 & 5.77 & -12.20 & 14.78 \\
\hline Eurostat & 197 & 1.83 & 0.99 & -0.60 & 4.10 \\
\hline Eurostat & 196 & 9.57 & 1.35 & 7.20 & 12.10 \\
\hline
\end{tabular}




\section{A.2. Series used for the shadow rates}

\begin{tabular}{lrrrr}
\multicolumn{1}{c}{ Yield maturity } & Mean & Std. Dev. & Min & Max \\
\hline \hline 3 month & 1.32 & 1.41 & -0.56 & 4.21 \\
6 month & 1.44 & 1.41 & -0.50 & 4.32 \\
9 month & 1.53 & 1.41 & -0.47 & 4.43 \\
1 year & 1.62 & 1.41 & -0.45 & 4.51 \\
2 years & 1.85 & 1.39 & -0.42 & 4.66 \\
3 years & 2.1 & 1.36 & -0.39 & 4.69 \\
4 years & 2.28 & 1.33 & -0.32 & 4.69 \\
5 years & 2.49 & 1.29 & -0.21 & 4.71 \\
6 years & 2.69 & 1.26 & -0.08 & 4.73 \\
7 years & 2.87 & 1.23 & 0.06 & 4.75 \\
8 years & 3.03 & 1.21 & 0.19 & 4.79 \\
9 years & 3.16 & 1.19 & 0.32 & 4.83 \\
10 years & 3.28 & 1.17 & 0.44 & 4.86 \\
30 years & 3.97 & 1.01 & 1.27 & 5.55
\end{tabular}

